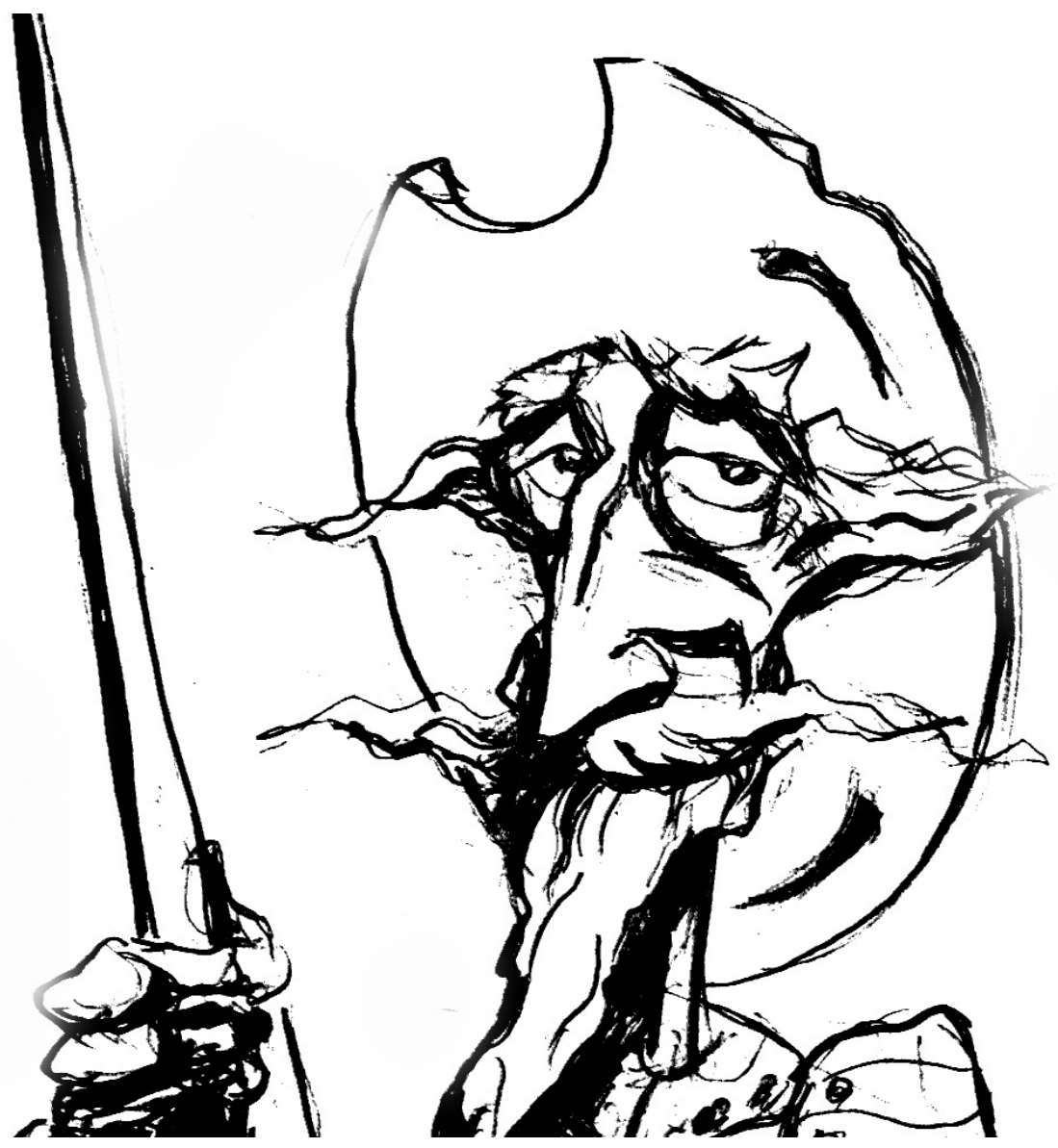

Apropiaciones simbólicas y ejercicio de la violencia en los viajes de circunnavegación de Francis Drake (1577-1580) y Thomas Cavendish (1586-1588)

[Malena López Palmero] 



\title{
Apropiaciones simbólicas y ejercicio de la violencia en los viajes de circunnavegación de Francis Drake (1577-1580) y Thomas Cavendish (1586-1588)*
}

\author{
Symbolic Appropriations and use of Violence in the Circumnavigation \\ Voyages of Francis Drake (1577-1580) and Thomas Cavendish (1586-1588)
}

MALENA LÓPEZ PALMERO

\section{Resumen}

A cinco siglos del primer cruce del Estrecho de Magallanes, se analizan las experiencias inglesas de Francis Drake (1577-1580) y Thomas Cavendish (15861588) con el propósito de reconstruir las apropiaciones simbólicas que los navegantes hicieron de la región fueguina y sus habitantes. Impresos, manuscritos, imágenes y mapas evocan a la alteridad americana más austral en tanto dispositivo de la competencia ultramarina entre Inglaterra y España. Asimismo, dan cuenta de las hostilidades con los nativos desatadas durante el cruce, interpretadas en función de los objetivos de los viajeros y su validación autoral. De allí que el trabajo enfatice los contrastes entre las dos experiencias de circunnavegación inglesas, dando cuenta de las condiciones de producción de sus representaciones.

\section{Abstract}

Five centuries after the first crossing of the Magellan Strait, the English experiences of Francis Drake (15771580 ) and Thomas Cavendish (1586-1588) are analyzed with the aim of reconstructing the symbolic appropriations that the navigators made on the Tierra del Fuego region and its inhabitants. Printed books, manuscripts, images and maps evoke the southernmost American otherness as a device of the overseas competition between England and Spain. Besides, they show the hostilities with the Natives unleashed during the crossing, which were seen according the travelers' objectives and their validation as authors. Hence this work emphasizes the contrasts between the two English circumnavigation experiences, giving an account of the conditions in which their representations were made.

\section{Keywords}

Magellan Strait; Francis Drake; Thomas Cavendish; Representations; XVI ${ }^{\text {th }}$ Century.

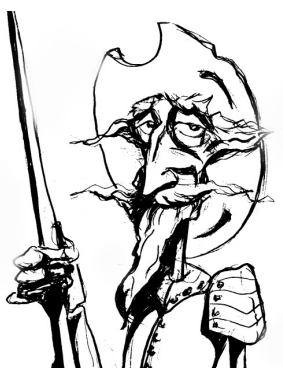

Recibido con pedido de publicación el 25 de febrero de 2020

Aceptado para su publicación el 5 de mayo de 2020

Versión definitiva recibida el 10 de junio de 2020

Malena López Palmero, Universidad de Buenos Aires, Universidad Nacional de San Martín, San Martín, Argentina; email: mlpalmero@unsam.edu.ar

\footnotetext{
* Agradezco las sugerencias de las/los evaluadoras/es de la revista.

Esta obra se publica bajo licencia Creative Commons. Atribución-NoComercial-CompartirIgual $(\mathrm{cc})$ EY-NC-SA 4.0 Internacional

López Palmero, Malena "Apropiaciones simbólicas y ejercicio de la violencia en los viajes de circunnavegación de Francis Drake (1577-1580) y Thomas Cavendish (1586-1588)", Prohistoria, Año XXIII, núm. 34, dic. 2020, pp. 39-74.
} 


\section{Introducción}

Los viajes de circunnavegación de Francis Drake (1577-1580) y de Thomas Cavendish (1586-1588) son hitos indiscutibles de los orígenes del imperialismo inglés. Dichas proezas marítimas abrieron un nuevo frente de conflicto entre Inglaterra y España en el Océano Pacífico. Con el despliegue de las violentas prácticas depredatorias de los ingleses sobre barcos y puertos españoles, tuvo lugar una disputa de índole intelectual sobre la apropiación de los espacios, con sede en los libros de viajeros.

En relación con la región del Estrecho de Magallanes, los navegantes ingleses denunciaron $\mathrm{y}$ desprestigiaron a sus primeros descubridores $\mathrm{y}$ moradores ibéricos. La desacreditación del presunto "gigantismo" de los "patagones", junto con las descripciones de un paisaje tan desolado como fascinante, abonan a la construcción de un territorio hostil y, a causa de ello, desprotegido. En la proposición de topónimos, como hiciera Cavendish al nombrar Puerto Hambre a la Ciudad del Rey Don Felipe fundada por Pedro Sarmiento de Gamboa (1584), también se alojaba la intención de denostar el colonialismo español.

La disputa simbólica del Estrecho de Magallanes es considerada aquí desde el punto de vista de la historia cultural, a partir de la indagación de las representaciones sobre el espacio y los habitantes americanos en función de un contexto histórico signado por la rivalidad política y religiosa mantenida entre las potencias del cuadrante noroeste de Europa y los imperios ibéricos. Se asume que, más allá de que no fuera el objetivo de las empresas de Drake y Cavendish establecerse en la zona Estrecho sino cruzarlo para conseguir otros propósitos de rédito más inmediato, las representaciones que legaron sus viajeros contribuyeron en buen grado a la construcción de un discurso legitimador de la expansión ultramarina inglesa. ${ }^{1}$ Los testimonios sobre el cruce del Estrecho de los viajes de Drake y Cavendish coinciden en la crítica a los antecesores viajeros españoles, en la demostración de fuerza militar frente a los indígenas (en diferentes grados según se trate del viaje de Drake o de Cavendish) y en las proyecciones sobre un posible dominio inglés de la región fueguina (plasmadas en topónimos, mapas y un atento detalle de las fuentes de abastecimiento).

\footnotetext{
${ }^{1}$ Los textos y las imágenes, en tanto representaciones, se analizan aquí tanto por su contenido como por su condición de dispositivos en la disputa por el poder colonial. Siguiendo la taxonomía de Louis Marin, a la cualidad transitiva de las representaciones, que implica volver a presentar lo ausente, se le agrega la consideración sobre el poder, derivada de su propiedad reflexiva. Esta implica que, al "presentarse como representando algo" (Chartier, 2001: 82), la representación tenga efectos "del afecto y del sentido", creando o recreando una relación de poder sobre del público, la cual recorre desde la lealtad a la devoción, pero siempre en un estado "apremiante, obligatorio y legítimo" (Marin, 2009: 148).
} 
Además de las experiencias y representaciones de cada uno de los viajes analizados aquí, es importante señalar el efecto que tuvieron para la expansión inglesa en sus momentos iniciales. La publicación de los relatos en la obra de Richard Hakluyt, su compilador, contribuyó a la construcción de una verdadera "épica de la moderna nación inglesa". ${ }^{2}$ Para la época en que Hakluyt lanzó su Principall Navigations, Voyages and Descoveries of the English Nation (1589), los ingleses todavía estaban muy lejos de poder establecer una colonia en América. Un primer intento de colonización de Virginia (en la isla de Roanoke, actual Carolina del Norte, entre 1585-1586), había sido abandonado tras un año de afrontar la carestía y la confrontación con los indígenas. También habían fracasado dos intentos posteriores por recuperar esa colonia (en 1587 y 1590). El mismo libro compilaba los relatos de las campañas en búsqueda de un pasaje interoceánico en la región ártica durante las décadas de 1570 y 1580. Aunque estos intentos fracasaron en su propósito, incluso con ostensibles pérdidas materiales y humanas algunos de ellos, alimentaron las ambiciones de colonización en América del Norte. ${ }^{3}$

Considerados en el conjunto de experiencias ultramarinas inglesas de finales del siglo XVI, los relatos de los viajes de circunnavegación de Drake y Cavendish se distinguieron por sus proezas navales, las cuales permitieron pensar en nuevas estrategias para competir con España en ultramar. El comercio de la especiería en las Islas Malucas, que tanto Drake como Cavendish explotaron a su paso por el Pacífico, constituyó un antecedente para la creación de rutas más estables, como la que monopolizó la Compañía de Indias

\footnotetext{
2 El término fue acuñado por J. A. Froude (1852), un "profeta del despertar imperial" (Quinn, 1974: I-148), pero ha sido adoptado en general por la historiografía, cuyos aportes más críticos y recientes distinguen las pretensiones imperialistas de su producción original de las apropiaciones ideológicas de tiempos posteriores.

${ }^{3}$ Las primeras expediciones de descubrimiento estuvieron a cargo del capitán Martin Frobisher, con el apoyo financiero del flamante consorcio de comerciantes de la Compañía de Catay. Fueron tres viajes consecutivos, durante los veranos de 1576, 1577 y 1578. Del primero de ellos se obtuvo muestra de un mineral de pirita de hierro, más popularmente conocido como el "oro de los tontos", que sirvió como principal estímulo de los dos viajes subsiguientes. A pesar de que el mineral demostró no tener valor alguno y de que las dificultades de una navegación en aguas heladas limitaron las exploraciones a la zona sur de la Isla de Baffin (puntualmente, la bahía que llevaría el nombre del capitán) y a las inmediaciones del estrecho de Hudson, la región ártica siguió siendo atractiva para exploradores ingleses durante las décadas siguientes. Un intento de colonización en esa región, llevado a cabo por Sir Humphrey Gilbert en 1583, fracasó dramáticamente. John Davis llevó a cabo tres viajes en 1585, 1586 y 1587, los cuales se concentraron especialmente en el suroeste de Groenlandia y el estrecho que separa a esta de la Isla de Baffin. Aunque la contribución de Davis se limitó a una ampliación del saber geográfico, sus viajes fueron concebidos como un antecedente para las pretensiones inglesas sobre el norte del continente americano, especialmente para posicionarse mejor en el negocio de las pesquerías en Terranova. Allí también concurrían, desde mediados de siglo, pesqueros vascos, portugueses y franceses, pero la actividad alcanzó un verdadero despliegue en las décadas de 1580 y 1590 (Appleby, 2001: 68).
} 
Orientales desde su fundación, en 1600. Otra estrategia, la de hallar el extremo occidental del mentado pasaje interoceánico, en el Estrecho de Anián, no fue más allá del arriesgado intento de Drake. ${ }^{4}$

Pero acaso el efecto más importante de los viajes de circunnavegación de Drake y de Cavendish fue que más y más navegantes ingleses se lanzaran a atacar y robar barcos y puertos españoles en las costas americanas. El botín capturado por Drake fue tan extraordinario (especialmente por la captura del galeón conocido como Cacafuego, frente a la costa del Cabo San Francisco, en Ecuador) que la reina autorizó a dejar en sus manos "tantos lingotes traídos a casa por él como para alcanzar la suma de diez mil libras" (Nuttall (ed.), 1914: 429). ${ }^{5}$ Cavendish encontró a los españoles del Pacífico mejor preparados en la defensa, pero logró destruir quince barcos, entre ellos un galeón cargado con finas mercancías orientales en la Baja California. ${ }^{6}$

Ciertamente, el pillaje era una estrategia corriente de los navegantes ingleses en aguas europeas y uno de los puntos principales de las negociaciones diplomáticas entre España e Inglaterra en la década de 1560, al punto tal que se creía que la reina y su consejo eran encubridores de los piratas por no castigarlos como se reclamaba desde Castilla. ${ }^{7}$ Paralelamente, se llevaron adelante campañas de comercio de esclavos en el Caribe, comandadas por John Hawkins y en las que participó su primo segundo, Francis Drake. Una vez

\footnotetext{
${ }^{4}$ La búsqueda del paso interoceánico en el Pacífico Norte fue uno de los objetivos de Drake, como la opción más corta y atractiva para regresar a Inglaterra. Las proyecciones geográficas de la época subestimaban la distancia del pasaje (Parry 1984: 7), además de hacer una incorrecta valoración de las condiciones climáticas. Cuán lejos llegó Drake en la búsqueda del estrecho de Anián es objeto de debate, aunque el globo terráqueo de Molyneux (1592), que recoge el viaje de Drake, indicaría los $48^{\circ}$ de latitud norte (Wallis, 1984: 130).

${ }^{5}$ En la "Carta de la reina Isabel a E. Tramayne, ordenando que la suma de $£ 10.000$ debía dejarse en manos de Francis Drake" (de 22 de octubre de 1580), también se indica a Tramayne, funcionario del Consejo Privado, que guarde el mejor secreto sobre la mencionada suma concedida (Nuttall, 1914: 429-430). Esta complicidad señala el favoritismo de la reina por Drake, quien fue elegido alcalde de Plymouth en 1580 y nombrado caballero en abril de 1581, nada menos que en la cubierta del Golden Hind. Para entonces su fortuna era tan espectacular que compró una abadía en Devon (Buckland Abbey), donde residió hasta su muerte. Además, fue miembro del Parlamento por un distrito de Cornualles (Cornish) desde 1584 y vicealmirante en 1588 (durante la guerra con España). Su posición le permitió hacer negocios privados (la construcción de una represa en Plymouth, en 1590-1591) y destinar su fortuna en las campañas de corso en América (1585-1586 y 1595-1596) (Gill, 1984: 84-99).

${ }^{6}$ Del Santa Ana Cavendish obtuvo una buena cantidad de oro y joyas, pero más importante aún de seda y porcelana. Las mercancías de lujo de este tipo, obtenidas mediante el pillaje, eran reexportadas desde Inglaterra por las compañías comerciales del Levante y de Moscú, aunque no se descarta que circularan también en la región del Báltico (Quinn y Ryan, 1983: 143).

7 Un funcionario de la embajada española en Londres, Luis Román, escribe a Felipe II en febrero de 1564 que "la Reyna y su Consejo son los encubridores destos ladronicios, pues no los quieren remediar" (Archivo General de Simancas, Estado-Legajo 0817, fol. 1v). Se adapta esta transcripción original a los usos del español actual.
} 
desautorizado este tipo de incursiones por la reina de Inglaterra, que intentaba contener una posible guerra con España, se dio paso a un activo período de piratería (1568-1585), siguiendo la clasificación de las intervenciones inglesas en ultramar propuesta por Kris Lane (1998: 33). ${ }^{8}$ El devastador viaje de circunnavegación de Drake tensó todavía más la precaria paz entre los reinos, y un nuevo raid en las Indias Occidentales, entre 1585-1586, terminó por romperla, dando paso al período de corso (1585-1604).

Aunque esta clásica periodización es coherente con el desenvolvimiento de una conflictividad creciente entre las potencias europeas, ${ }^{9}$ no resulta concluyente respecto de las estrategias navales inglesas. La corona inglesa apoyó discretamente a las campañas Hawkins y Drake ${ }^{10}$ antes y después de declarada la guerra. Isabel no solo autorizó las campañas, sino que aportó barcos y dinero para aprovisionarlos y también participó de los dividendos. En la medida en que las incursiones depredatorias de los navegantes ingleses en las exclusivas aguas americanas constituyeron un servicio al reino, resulta legítimo y más adecuado aplicar la noción de "corso-piratería" propuesta por Mickaël Augeron (1997) para el caso francés en el mismo período. La corsopiratería era en todo congruente con la idea de que, atacando a España en sus dominios americanos, los ingleses obtendrían mejores resultados que en una guerra convencional en el Viejo Mundo, especialmente si ello permitía incautar el tesoro que estaba destinado a sostener las campañas militares en Europa (Elliott, 1972: 115). ${ }^{11}$

\footnotetext{
${ }^{8}$ Drake participó entre 1566 y 1567 de los viajes de contrabando de esclavos de su pariente John Hawkins (a la sazón, continuador de la empresa de su padre, William) en los dominios españoles del Caribe. Una represalia española en San Juan de Ulúa (1567) comportó serias pérdidas para Hawkins y tensó las relaciones entre España e Inglaterra. Desde entonces, la reina Isabel desaprobó los viajes negreros (que había autorizado y financiado parcialmente en secreto) y Drake se abocó a atacar a los españoles en el Caribe y en el Istmo de Panamá, en los viajes de 1570, 1571 y 1572-73 (Silverberg, 1997: 245-251).

${ }^{9}$ Los asuntos de ultramar vinieron a precipitar un conflicto que tenía diversas aristas, como la intervención militar de Inglaterra en Países Bajos a favor de los sublevados protestantes o la complicidad entre España y las fuerzas católicas de la monarquía escocesa bajo María Estuardo. ${ }^{10}$ En una petición de Hawkins a las autoridades coloniales españolas (de Borburata, en el Reino de Nueva Granada), el capitán inglés declaraba que el viaje se hacía por "orden de Isabel, reina de Inglaterra, mi señora, cuya flota es esta" (Wright (ed.), 1929: 82). Para el viaje de circunnavegación de Drake aportaron a título individual el militar jerárquico Christopher Hatton (por quien Drake renombró Golden Hind al Pellican), el conde de Leicester y Sir Francis Walsingham (Quinn y Ryan, 1983: 82). El viaje alrededor del mundo de Cavendish fue autorizado por la reina, pero financiado por el propio capitán, quien debió hipotecar sus tierras para tal efecto (Silverberg, 1997: 337).

${ }^{11}$ Richard Hakluyt era consciente de que "las fechorías cometidas con el tesoro indígena en tiempos de Carlos, el último emperador, padre del rey español, deben ser consideradas por la reina, su más excelente majestad, ya sea porque el arribo continuo del dicho tesoro (...) produce molestias irrecuperables a este reino, de las cuales ya hemos tenido experiencia muy peligrosa" (Hakluyt, 1877 [1584]: 3-4).
} 
La delicada situación en que hallaba la corona inglesa al brindar apoyo a los atacantes de un reino con el que aún no estaba preparada militarmente para romper, explica el estricto secreto que se mantuvo sobre el viaje de Drake. Pero, ciertamente, la falta de registro oficial fue una constante en todo el período, a causa de la enorme autonomía (Canny, 2001: 4; Pagden, 2001: 55; Games, 2008: 691) que gozaban las empresas de corso-piratería, por ser emprendimientos privados para los que la corona apenas oficiaba como un inversor más y no como comitente. A ello se debe la carencia de documentación acerca los propósitos de los viajes aquí analizados, ${ }^{12}$ que por esa razón direcciona el estudio a los testimonios de las experiencias editadas en libros de viajes. Estos últimos contienen elementos para la construcción de un programa imperial, en cuanto proveen informaciones útiles para futuros viajeros (sobre geografía, clima, habitantes nativos, riquezas y poder defensivo de España) pero también sugieren o presentan argumentos justificatorios para un dominio inglés en América. Ello no equivale a formular una ideología del imperio, la cual recién tomó cuerpo en la primera mitad del siglo XVIII, sino que invita a analizar los orígenes de una dinámica expansionista que consolidó progresivamente su carácter protestante, comercial, marítimo y libre (Armitage, 2004: 8). ${ }^{13}$

En este trabajo se analizan las narrativas de los viajes de Drake y Cavendish en su paso por el Estrecho de Magallanes ${ }^{14}$ con el objetivo de reconstruir las apropiaciones simbólicas de los viajeros ingleses, moldeadas

${ }^{12}$ El único documento existente sobre los objetivos del viaje de Drake señala a Egipto como destino, lo cual remite a la política del secreto vigente. Para la controversia historiográfica sobre los propósitos de Drake, ver López Palmero (2016: 195-196). Esta y las subsiguientes citas en lengua extrajera han sido traducidas por la autora.

${ }^{13}$ A diferencia de los imperios ibéricos, no hubo en Inglaterra un "lenguaje" del imperio propio del discurso político (Armitage, 2004: 7). La evangelización fue expresada en algunos discursos expansionistas de la segunda mitad del siglo XVI (Hakluyt, 1877 [1584]), aunque siempre subordinada al objetivo principal: el comercio. Como sostiene Anthony Pagden, esto se desprende del escaso peso que tuvo la teoría calvinista en los intentos ingleses por legitimar su presencia en América y del rechazo a la idea de conquista (que en la práctica no resultó otra cosa que la exclusión o aniquilación de los indígenas) (Pagden, 2001: 37-40).

${ }^{14}$ Los relatos impresos se condensan principalmente en dos obras: la postergada edición atribuida a Francis Fletcher, The World Encompassed by Sir Francis Drake (1628), y la primera y segunda edición de la colección de Richard Hakluyt, Principal Navigations (1589 y III:1600), donde se hallan: "The famous voyage of Sir Francis Drake into the South Sea, and there hence about the whole Globe of the Earth, begun in the yeere of our Lord, 1577" ([Hakluyt],1589: s/p); "The relation of a voyage made by a pilot called Nuno da Silva..." (da Silva, 1600: 742-748); "The voyage of M. John Winter into the South sea by the stright of Magellan, in comfort with M. Francis Drake, begun in the yeere 1577" (Cliffe, 1600: 748-753); "The worthy and famous voyage of Master Thomas Candishe made round the globe of the earth, in the space of two yeeres and lesse then two monethes, begun in the yeere 1586" (N. H, 1589: 809-813); y "The admiral and prosperous voyage of the worshipfull Master Thomas Candish in the countie of Suffolke Esquire, into the South sea, and from thence round about the circumference of the whole earth, begun in the yeere of our Lord 1586, and finished 1588" (Pretty, 1600: 803-825). 
tanto por la rivalidad entre Inglaterra y España como por los conflictos mantenidos con los habitantes locales. Para ello, se recrea el contexto de producción de los textos y el diálogo necesario que mantienen con otros (Burke, 2002), sean antagonistas o "dignos" referentes, para demostrar que las representaciones sobre la geografía y los habitantes patagónicos fueron verdaderos dispositivos del naciente imperialismo inglés.

\section{Derroteros editoriales de los viajes de circunnavegación ingleses}

El relato sobre el primer viaje de circunnavegación inglés, realizado por Francis Drake, tuvo un peculiar derrotero editorial (López Palmero, 2016). Aunque el viaje había alcanzado una fama asombrosa y se difundía en obras publicadas en Europa continental, como fue el caso de los Les Trois Mondes de Henri Lancelot Voisin de La Popelinière (1582), en Inglaterra se mantuvo en una suerte de secreto por algunos años. Eso se debió a la prohibición de la publicación por parte de la reina Isabel, quien intentaba evitar entrar en guerra con España. ${ }^{15}$ Pero una vez que las fuerzas de Inglaterra y España se enfrentaron en el Mar del Norte, con la derrota de la Armada Invencible española como resultado, en 1588, las humillaciones sufridas por España a manos de Drake cobraron relevancia editorial.

Ello explica en parte ${ }^{16}$ la tardía publicación del relato del primer viaje de circunnavegación inglés, en la compilación de Richard Hakluyt (1552-1616), Principall Navigations, en 1589. Se trata de un relato anónimo, en el que el propio Hakluyt habría compilado sintéticamente la información provista por los manuscritos a los que tuvo acceso, ${ }^{17}$ titulado "The famous voyage of Sir Francis

\footnotetext{
${ }^{15}$ El interés de La Popelinière por el viaje de Francis Drake se debía a la expectativa, que en Francia duró hasta el siglo XVIII, de ocupar un quinto continente o Tierra Austral (Martínez, 2019: 63). Más allá de que Drake hubiera tenido dentro de sus objetivos el de descubrir ese territorio, como afirmó E. G. R. Taylor (1930: 46-47), el carácter secreto del viaje de Drake se atribuyó en la época a la decisión de la reina de retener la información "para que no fuera comunicada a los extranjeros o incluso a sus súbditos" (La Popelinière 1582: III-36v.).

16 El descubrimiento de lo que fuera llamado Estrecho Drake constituía una información estratégica en la competencia ultramarina que instó a conservar en secreto la relación del viaje de Drake (Martinic, 1998:7). Además de la política de estado, el accionar particular de Drake habría causado la reticencia por parte de las máximas autoridades del reino. Un episodio controvertido -la ejecución del aristócrata Thomas Doughty en el cabo San Julián- desaconsejaba la publicación del viaje. Además, el Secretario de Estado Francis Walsingham le retiró su apoyo a Drake cuando este fracasó en sus ataques a La Coruña y Lisboa, en la primavera de 1589 (Quinn, 1996: 20). Walsingham aprobó la publicación del viaje de Drake recién después de desatado el combate contra la Armada Invencible (López Palmero, 2016: 197-198).

17 Uno es la "Narrativa" de John Cooke, quien cargó las tintas sobre el autoritarismo de Drake respecto al affaire Thomas Doughty. Esa parte del relato fue desacreditada por el propio Hakluyt, quien habría justificado con su propio puño los sucesos de San Julián, y posteriormente por la historiografía de principios del siglo $\mathrm{XX}$, como es el caso de la compilación de los viajes de Drake a cargo de Zelia Nuttall (1914). El otro testimonio habría sido
} 
Drake into the South Sea, and there hence about the whole Globe of the Earth, begun in the yeere of our Lord, 1577" ([Hakluyt] 1589: s/p). El "famous voyage...", con sus aproximadamente 10.000 palabras, se incluyó en el volumen como una adenda de seis hojas, sin numerar, entre las páginas 643 y 644. Ello indica, a todas luces, que la decisión de incluir el relato del viaje de Drake se tomó de forma muy precipitada, una vez que el libro estuvo impreso, pero antes de que fuera puesto en circulación. ${ }^{18}$ Kenneth R. Andrews afirmó que Hakluyt, "habiendo aceptado bajo presión no publicar un relato del viaje [de Drake], evidentemente recibió permiso para hacerlo luego de que la edición de 1589 fue completada" (Andrews, 1974: I- 274).

Para la segunda edición aumentada de Principall Navigations (Hakluyt, 1598-1600), se mantuvo el "famous voyage..." con unas pocas correcciones y se agregaron otros dos testimonios del viaje: el de Edward Cliffe (quien viajó a bordo del Elizabeth, capitaneado por John Winter) y el del portugués Nuno da Silva, un piloto que había sido capturado por Drake en Cabo Verde. El texto atribuido al capellán de la expedición de Drake, Francis Fletcher, fue publicado recién en 1628, y constituye una de las fuentes más completas del viaje, a pesar de presentarse como una defensa del liderazgo de Drake. ${ }^{19}$

El viaje de circunnavegación de Cavendish tuvo inmediata repercusión en la primera edición de Principall Navigations. "The worthy and famous voyage of M. Thomas Candish..." (N. H, 1589: 809-813) se ha atribuido a Robert Hues, ${ }^{20}$ un matemático que acompañó a Cavendish en su periplo alrededor del mundo y que ayudó a Hakluyt a reunir y editar el material de esa experiencia (Wallis, 1974: 229). ${ }^{21}$ Para la segunda edición, Hakluyt incorporó el relato de Francis

el anónimo "Discourse of Sir Francis Drake iourney \& exploytes after hee had past ye Straytes of Megellan". El testimonio de Cooke permaneció inédito hasta 1854 (Vaux (ed.), 1854: 187-218), mientras que el anónimo se conserva en manuscrito en la British Library (Harleian MS 280, ff. 83-90).

${ }^{18}$ Esto último se deduce de un dato estadístico: de los 121 ejemplares conservados de Principall Navigations (1589), solo 10 no contienen el "Famous voyage" (Quinn, Armstrong y Skelton, 1974: 481-489). De los dos ejemplares consultados por la autora en la Biblioteca John Carter Brown, uno contiene la adenda de las 12 páginas, mientras que el otro no.

${ }^{19}$ La edición de The World Encompassed estuvo a cargo de un sobrino homónimo de Francis Drake y contó con la colaboración de Philip Nichols.

20 Tomando como conjetura que habría habido un error de imprenta, confundiendo $\mathrm{N}$ por $\mathrm{M}$, que habría indicado "Master Hues" (Wallis, 1974: I- 229).

${ }^{21}$ Hakluyt incluyó la "Muy exacta y perfecta descripción de las distancias de un lugar a otro, desde el Río de la Plata hasta llegar a Pette Guaras...", atribuida a Lopes Vas (1589: 803-808). Como indica su título, el diario no aporta información sobre la experiencia de los viajeros por el Estrecho, sino que se trata de una descripción geográfica. Se ha desconfiado de la autenticidad del texto por ser testimonio de segunda mano, ya que se basa en una entrevista con Nuno da Silva (Wallis, 1974: I-231) e incluye relatos del viaje de Cavendish, lo cual se deduce de su mención al "pueblo llamado Nombre de Jesús" (Lopes Vas, 1589: 807. Este texto es el que se piensa que recicló Hakluyt para su reedición en 1600 (Quinn y Quinn, 1974: 456). 
Pretty, "The admiral and prosperous voyage" (Pretty, 1600: 803-825), probablemente cedido por el propio Cavendish antes de la partida de su último viaje de 1591. Francis Pretty era un caballero de Suffolk, y acompañó a Cavendish en la aventura a bordo del Hugh Gallant. Su relato es más extenso que el rubricado por N. H., por lo que incluye ciertas informaciones ausentes en la narrativa de este último y se detiene en descripciones sobre los lugares y sus habitantes, haciendo más atractivo el relato. Según Helen Wallis, el tono más "gráfico" de Pretty fue probablemente el motivo por el que Hakluyt reemplazó a la narrativa "útil pero seca" de N. H. por la más atractiva de Pretty en su segunda edición de Principall Navigations (Wallis, 1974: 231).

En cuanto a este último viajero, que rodeó el globo en las dos oportunidades, es preciso aclarar algunos malentendidos, ya que el viejo error (Greenhow, 1844: 73) 22 de considerar a Pretty como el autor del "famous voyage" correspondiente al viaje de Drake, reescrito y publicado por Hakluyt en 1589, sigue vigente (Bueno Jiménez, 2013: 51). Ello apenas puede atribuirse a la coincidencia de los títulos con los que fueron impresos sus relatos en las dos ediciones de la colección de Hakluyt. La confusión se debe más bien a la aparición en Francia del anónimo relato de la circunnavegación de Drake (1613, reimpreso en 1627 y reeditado en inglés en 1752). A principios del siglo XIX se atribuyó la autoría de ese relato a un "noble picardo" de la expedición de Drake, y poco más tarde se identificó a ese aristócrata con Francis Pretty. Travers Twiss (1846: 25-31) analizó minuciosamente la secuencia de errores que llevaron a identificar el "Famous voyage" con Pretty, pero ello no impidió que Harvard publicara "Sir Francis Drake's famous voyage round the World, by F. Pretty" (Pretty, 1910), texto que con sus reediciones (2005) y versiones digitales ${ }^{23}$ continúa nutriendo a los estudios sobre el tema. No obstante, tanto la coincidencia del título del relato como cierta información precisa (las latitudes coinciden con la versión de Hakluyt de 1589, no así con la de 1600 que este corrigió) no dejan dudas de se trata de un compendio del "Famous Voyage" preparado por Hakluyt y editado en 1589.

A pesar de que el viaje de Cavendish no tuvo la gloria del de Drake en cuanto a la cantidad de sobrevivientes y de fortunas confiscadas a españoles, sí

\footnotetext{
${ }^{22}$ En nota al pie de página, Greenhow aclara que tomó las citas del "Famous Voyage of Sir Francis Drake, de Francis Pretty, uno de la tripulación del barco de Drake, escrito por pedido de Hakluyt y publicado por él en 1589. Es un relato llano y sucinto de lo que el escritor vio o creyó que ocurrió durante el viaje, y cuenta con todas las marcas de verdad y autenticidad" (Greenhow, 1844: 73). Resulta interesante el hecho de que la cuestión de la autoría del "Famous voyage" recobrase energía en el contexto de las negociaciones limítrofes entre Estados Unidos e Inglaterra sobre el territorio de Oregón (de ocupación conjunta entre 1818-1846). El viaje de Drake, particularmente por el descubrimiento del litoral pacífico norte, fue tomado como material probatorio de las negociaciones que desembocaron en el Tratado de Oregón (1846).

${ }^{23} \mathrm{https}$ ://sourcebooks.fordham.edu/mod/1580Pretty-drake.asp y

https://www.gutenberg.org/files/2991/2991-h/2991-h.htm (consultados el 31/12/2019).
} 
contó con una extensa cobertura en la colección de Hakluyt. ${ }^{24}$ Sin dudas ello se debió a circunstancias favorables, ya que el viaje se realizó en un contexto de abierto enfrentamiento entre España e Inglaterra, lo cual eximía al texto de ser considerado una provocación, tal como se pensaba del viaje de Drake. Pero también las redes personales entre viajeros y editores ingleses pusieron al viaje de Cavendish en una situación de privilegio. Douglas Cavendish, la primera esposa y madre del único hijo de Hakluyt, era pariente del navegante (probablemente prima). Además, Hakluyt fue nombrado beneficiario del testamento de Cavendish, redactado en septiembre de 1587 (Mancall, 2008: 179). El vínculo personal habría facilitado la participación de Cavendish en la empresa colonizadora de Walter Ralegh en Virginia, en 1585, para la cual había colaborado Hakluyt como intelectual y figura influyente en la corte, junto con su primo homónimo, el abogado conocido como Hakluyt el Viejo.

Son notables las articulaciones entre el proyecto inglés de colonización en Virginia (1585-1586) y los viajes de exploración y pillaje. Como consta en el relato de Hues, Cavendish "fue capitán con Sir Richard Greenville hacia Virginia", en 1585, aunque regresó en seguida a Inglaterra. Este viaje le habría permitido recorrer "Canarias, y de allí a las islas de Dominica, La Española, San Juan de Puerto Rico, las Lucayas y Florida, en las Indias Occidentales" (N. H., 1589: 809). Para el autor del relato, este viaje hacia lo que sería la primera colonia inglesa en América convenció a Cavendish de hacer un viaje al Mar del Sur y, "consecuentemente, rodear al globo del mundo" (N. H., 1589: 809). Las conexiones entre piratería y proyecto colonial también fueron evidentes en el caso de Francis Drake, quien participó del proyecto colonial de Virginia embarcando a los desesperados colonos a Inglaterra, en 1586, aprovechando su recalada en el fuerte, de regreso por un viaje dedicado a expoliar a los españoles en el Caribe.

Si hubo una obra destinada a promover la expansión ultramarina inglesa en general y a difundir la experiencia colonial en Virginia en particular, esta fue la colección de Grandes Viajes, o Americae, de Theodore de Bry (c. 1528-1598). ${ }^{25}$

\footnotetext{
${ }^{24}$ Hakluyt también publicó "A letter of Master Thomas Candish to the right honorable the Lord Chamberlaine touching the successe of his voyage about the world" [9 de septiembre de 1588] (Cavendish, 1589: 808) y "Certain notes, and references taken out of the large Mappe of China brought home by Master Thomas Candish" (1589: 813-815). La ponderación del texto de Cavendish en la colección del joven Hakluyt se pone de manifiesto en el texto de Hues, quien hace una alabanza al capitán, al resaltar que el viaje que llevó a cabo "con invencible coraje, excelente gobierno e increíble celeridad, para gran admiración de todos los hombres de juicio" (N. H, 1589: 809).

${ }^{25}$ El primer tomo de la colección, lanzado en 1590, se destinó al intento inglés de colonización de Roanoke incluyó el testimonio de Thomas Hariot, Brief and True Report, publicado originalmente en 1588 e incorporado en Principall Navigations al siguiente año. Más que "inspirado" (Van Groesen, 2008: 3), de Bry fue persuadido y asistido por Hakluyt para el lanzamiento de la colección, que indudablemente dio a la experiencia colonial inglesa una
} 
Este prestigioso grabador flamenco también preparó la edición de los viajes de circunnavegación ingleses para su octavo tomo, que terminaron por publicar, en latín y en alemán, sus hijos Johan Théodore y Johan Israel tras su muerte. Fue así como en 1599 lanzaron el Americae Pars VIII (de Bry (ed.), 1599) en la que se incluyó "Primero, a la descripción de los tres viajes del nobilísimo y vigoroso Francis Drake...", ${ }^{26}$ y "Segundo, el viaje de Thomae Candisch, quien recorriera en dos años un área de 13.000...". ${ }^{27}$ Para la cobertura del viaje de circunnavegación de Drake se utilizó el "famous voyage" de Hakluyt (1589), mientras que para el de Cavendish, el testimonio de Francis Pretty que el mencionado editor inglés publicara recién un año después. ${ }^{28}$

Si los testimonios de época, como los hasta ahora apuntados, son los materiales ineludibles para el estudio de la construcción de un imaginario sobre América y los americanos, se cuenta además con aquellos que vieron la luz muchísimo tiempo después y que sirven como contrapunto de los primeros. Este es el caso del juicio inquisitorial al piloto portugués Nuno da Silva en Nueva España en 1578, acusado por haber colaborado con los ingleses (Nutall (ed.): 1914:), ${ }^{29}$ o el de los testimonios españoles sobre el derrotero destructivo de Drake en el Pacífico (Fuensanta del Valle et. al. (eds.), 1889). Los documentos manuscritos completan el conjunto de materiales que aportan densidad al análisis, no solo por la nueva información acontecimental que puedan proveer para completar o poner en tensión las fuentes éditas, sino también por la

difusión extraordinaria en el continente, con su edición especial en cuatro lenguas (latín, inglés, francés y alemán).

26 Y sigue: “...quien atravesara primero la totalidad de la esfera terrestre y luego, junto al nobilísimo caballero Iohanne Havckens [John Hawkins], navegó en las Indias para conquistar la ciudad de Panamá, donde sus vidas acabaron" (de Bry y de Bry, 1599, s/p [portada]). Esta primera parte agrupa el viaje de circunnavegación de Drake y sus expediciones corsarias por el Caribe de 1585-1586 y 1595-1596.

${ }^{27}$ A diferencia de la primera parte en la que se compendian tres viajes, la segunda solo incluye el viaje de circunnavegación de Cavendish, de quien se remarcó su accionar militar, tal como se desprende de la continuación del título “...Contribuyó con el ejército inglés en el mar, atacando a todo aquello que apareciera en su itinerario" (de Bry (ed.), 1599, s/p [portada]).

${ }^{28}$ El curioso derrotero del texto de Pretty fue señalado por Benjamin Draper (1984: 201), quien identificó una primera edición en holandés (Ámsterdam, 1598), traducida por Emanuel Van Meteren a instancias de Richard Hakluyt, poseedor del original en inglés. De Bry tomó la edición holandesa para su traducción latina en la octava parte de Americae, antes de que apareciera en inglés por primera vez en el tercer tomo de Principal Navigations (1600). Recientemente, Alfredo Bueno Jiménez (2016: 236) identificó otra presunta fuente para la segunda parte: Thomas Candish's Voyage, de Thomas Pret (Londres, 1588), pero al momento no se encuentra evidencia de la existencia de ese texto, ni tampoco ha sido mencionado en la bibliografía especializada.

${ }^{29}$ La antropóloga y arqueóloga estadounidense Zelia Nutall descubrió el documento del juicio por casualidad en 1908 en los Archivos Nacionales de México. La Hakluyt Society de Londres preparó una edición especial para difundirlo. 
recurrencia a ciertas representaciones o interpretaciones que se hallan en la documentación impresa.

\section{Hostilidades en el espacio fueguino}

Los testimonios devenidos de los viajes de circunnavegación de Drake y de Cavendish demuestran que el contacto con los habitantes fueguinos fue decisivamente hostil. En ambos casos, hubo enfrentamientos que fueron provocados por los ingleses, pero la diferencia más evidente está en el modo en que los acontecimientos fueron presentados: mientras que los viajeros de Drake se detuvieron en la explicación de las causas y se esforzaron por encontrar cierta justificación de la violencia cometida contra los indígenas, los viajeros de Cavendish parecieron jactarse de ello.

El caso más resonante del paso de Drake por el territorio patagónico fue un enfrentamiento en el que los indígenas dieron muerte a un artillero, Olivier (o Mr. "Gunner"), que estaba haciendo demostración de tiro con su arco. Ello fue considerado por los indígenas como una amenaza, aunque Fletcher y Hakluyt lo mostrasen como un mero entretenimiento. ${ }^{30}$ Contrariamente a la interpretación de un supuesto malentendido, que se colige de los relatos de Fletcher y Hakluyt, Cliffe señala que los ingleses, que eran mayores en número que los arqueros nativos, subestimaron las advertencias que estos les hicieron a poco de hacer tierra: "el 22 de ese mes [junio de 1578] nuestro general [Drake], yendo desde la costa hacia tierra adentro con 7 u 8 de sus hombres, se encontró con 3 de los patagones que tenían arcos y flechas, que se acercaron haciendo señales de que se fueran" (Cliffe, 1600: 751). Drake vengó con sus propias manos a su artillero, y a su asesino

“disparó su lamento, que fue un rugido tan horrible $y$ espantoso como si diez con buena puntería, le arrancó su abdomen e intestinos con un gran tormento, como mostraba toros hubiesen rugido juntos. $\mathrm{Y}$ por ello el coraje de sus compañeros fue muy abatido y sus corazones horrorizados, y a pesar de ello algunos de sus compañeros y hombres del lugar salieron de los bosques de cada lado. Ellos estaban contentos de escapar y salvarse, y nuestros hombres sufriendo silenciosamente por [la diatriba de] partir o quedarse allí.

\footnotetext{
30 Fletcher y Hakluyt narran, con algunas diferencias menores, el desentendido que habría desembocado en el fatal enfrentamiento. Seis ingleses hacían un recorrido en tierra en busca de agua y provisiones, cuando se encontraron con "dos o tres" nativos. Olivier, el artillero, hizo una demostración de tiro de arco "por placer", a lo que siguió el intento de un tal Robert Winter, pero se le rompió la cuerda. Los indígenas habrían tomado ventaja de esta debilidad y comenzaron a atacar, y cuando Oliver "se aprestaba a disparar su arma de fuego, fue alcanzado mortalmente por una flecha" (Fletcher, 1628: 26-27; Hakluyt (ed.), 1589: s/p [2v]).
} 
Nuestro general decidió partir y luego tomar más revancha contra ellos" (Fletcher, 1628: 27).

Según Fletcher, no habrían tenido que reportar otro enfrentamiento con indígenas por el plazo de dos meses (Fletcher, 1628: 29). Pero el portugués Nuno da Silva dio cuenta de un enfrentamiento que, aunque coincide en fecha con el expuesto en fuentes inglesas, parece corresponder a un episodio diferente, que pasó de encuentro amigable a enfrentamiento mortal. Da Silva dio el mismo testimonio en su diario de viaje (da Silva 1579b: 281), en su indagatoria en Nueva España (1579a) y en el texto publicado por Hakluyt. En este último afirmó que cuatro indígenas fueron invitados a comer a bordo, y al retirarse y alcanzar cierta distancia,

"uno de los indios les gritó Magallanes, Esta he minha terra, que es Magallanes, este es mi país, y como los ingleses los siguieron, ellos huyeron tierra arriba hasta que en cierto punto volvieron y con sus flechas mataron a dos comerciantes ingleses: un inglés (sic) y otro holandés" (da Silva, 1600: III- 743). ${ }^{31}$

Si se entienden como dos episodios diferentes ocurridos el mismo día, 22 de junio de 1578, no uno (el artillero) sino tres miembros (sumando a los dos comerciantes) de la compañía de Drake perdieron la vida en las escaramuzas. Da Silva, además de hacer constar esta situación de vulnerabilidad de los ingleses (sin mencionar ninguna víctima indígena, como la que habría ocurrido tras la venganza de Drake relatada por los testigos ingleses), presentó una interesante analogía que remarcaba la autoridad exploratoria de la corona hispánica. Si los nativos interpelaron a los ingleses como "Magallanes" y reclamaron que aquella era su tierra, al denunciar su presencia también expresaban (o eso habría creído o intentado hacer creer da Silva) un

\footnotetext{
31 Destacado en el original (en letra redonda, siendo el resto de la obra en letra gótica). Este relato coincide con el que da Silva ofreció a los inquisidores de Nueva España. Como si se tratase del primer contacto entre ingleses e indígenas en el mes de junio de 1579, el portugués afirmó que "los [ingleses] que allí saltaron en tierra fueron seis hombres en busca de agua, y que antes que saliessen en tierra llegaron al batel quatro indios y les dieron los yngleses pan y vino. Después de haver comido los yndios se subieron en una cuesta arriba y decia un yndio dellos: Magallanes esta es mi tierra, y que fueron siguiendo a los yndios seis ingleses y habiendo subido un poco revolvieron los yndios y mataron un flamenco y un yngles, y los demas se bolvieron huyendo al batel" (da Silva, 1579a: 21). Pasaje cotejado con otra copia manuscrita de este relato que se encuentra en el Archivo General de Indias, Patronato 266 R 17, n 3. En el diario de viaje la información sobre el episodio se resume de la siguiente manera: "Día 22 [de junio de 1578]. Ese día, que era domingo, el capitán salió con doce hombres para remontar el río por una legua. Él hizo tierra con cuatro hombres armados con arcabuces, uno con un arco y otro con una espada y un escudo. Encontraron cuatro indios con arcos y flechas que habían comido y bebido con ellos. Después de que partieron, dispararon sus flechas y mataron a dos de la compañía" (da Silva, 1579b: 281). Traducción propia de la versión inglesa preparada por Nutall (1914), que es transcripción del ilegible original en portugués conservado en el Archivo General de Indias, Patronato 33, núm. 3, R 30.
} 
reconocimiento por el origen ibérico de los primeros exploradores a la región fueguina.

Al cotejar los testimonios ingleses con los de da Silva se deduce, de las omisiones y también de las justificaciones de los primeros, la intención por atenuar la información relativa a los conflictos, que podría haber despertado controversia con las autoridades inglesas. Pero a la vez, esta actitud era coherente con preocupación a intención de mostrar el éxito del viaje en términos militares, característica que se extrema en los relatos sobre el viaje de Cavendish. Lo que comparten las narrativas de ambos, sin embargo, es una mirada denostativa de los indígenas del Estrecho, que contrasta con la visión positiva de los indígenas del Río de la Plata $^{32}$ y mucho más con la exaltación de los habitantes locales de la Nueva Albión fundada por Drake.

Comparando las fuentes del viaje de Drake y de Cavendish, resalta la falta de escrúpulo de este último al referirse a los conflictos con los indígenas. Es decir, una completa despreocupación por la legitimidad de las acciones inglesas contra los habitantes locales. Los textos del segundo viaje de circunnavegación inglés se jactan de su superioridad militar, de la demostración de fuerza de sus viajeros. El testimonio atribuido a Robert Hues indica que los ingleses atacaron, en el Estrecho de Magallanes, a unos indígenas con los que incluso habían mantenido buen trato, por el mero hecho de ser considerados traidores:

“El 20 de enero [de 1587], a mitad de camino, divisamos salvajes de estatura razonable y fuimos hacia ellos, $y$ conferenciamos con ellos, pero eran tal su brutalidad y traición que nos habrían traicionado fingiendo amistad; pero nosotros, vislumbrando su traición, acometimos primero y cada uno de nuestros tiros eligió a su hombre, de modo que matamos a algunos, herimos a más, y el resto escapó" (N. H., 1589: 810).

Este mismo texto también da cuenta de ataques a comunidades de la costa africana, en Sierra Leona, donde sesenta hombres de Cavendish desalojaron a un pueblo y "saquearon las casas y las quemaron". En la "Ínsula Verde", quemaron "cerca de 150 casas por sus malos tratos con nosotros y con los cristianos" (N. H., 1589: 809). En su trayecto por el Océano Pacífico,

\footnotetext{
32 "Bajaron del país algunas gentes desnudas, llevando encima de sus cinturas solamente la piel de alguna bestia con su piel o pelo y también algo envuelto en sus cabezas. Sus rostros estaban pintados con diversos colores, y algunos llevaban sobre sus cabezas especies de cuernos. Cada hombre su arco, de un codo de largo, y un par de flechas. Ellos eran gente ágil y rápida para despachar y no parece que fueran ignorantes en los asuntos de la guerra, ya que al dar la orden de formar pueden aparecer algunos hombres" (Hakluyt (ed.), 1589: s/p [2r]). Los ingleses habrían presenciado una danza, circunstancia en la que a Drake le robaron su sombrero, lo cual retratado en la colección de de Bry (1599) tomando como epígrafe el pasaje alusivo de Hakluyt (1589: s/p [2r]). Una descripción más detallada está en Fletcher (1628: 22).
} 
Cavendish asaltó y posteriormente incendió al menos quince barcos españoles. En una carta dirigida a Lord Chamberlain, declaró que "a todos los poblados y pueblos en los que hice tierra, quemé y arruiné" (Cavendish, 1589: 808). Es importante señalar la tendencia, ya identificada en el viaje de Drake a partir de la nueva información provista por da Silva, de los textos a evitar aquellos episodios en los que los ingleses resultan heridos o muertos por ataques de poblaciones locales sin una posterior contraofensiva. Por ejemplo, el soldado inglés que murió por una flecha envenenada en Sierra Leona (Pretty, 1600: 804) o dos hombres que fueron heridos mientras lavaban la ropa en Puerto Deseado (Pretty, 1600: 805).

\section{El mito de los gigantes}

El topos del gigante americano es constitutivo de una epistemología de la exploración (Gallegos Gabilondo, 2018) que identifica a estos seres de proporciones fantásticas en los confines del mundo conocido, como demuestran los relatos fundadores de los viajes de Colón, Vespucio y Magallanes. El gigante como expresión de formación de saberes en el contexto de los grandes descubrimientos se ubica en el cruce de distintos géneros (el literario, el filosófico, el de la historia natural y el de la propia literatura de viajes) y tradiciones (la clásica y la medieval), atrayendo nuevas representaciones conforme al avance de las exploraciones. Representaciones que sedimentan sobre aquellas fundadoras y que alimentarán al mito hasta bien entrado el siglo XVIII, sin por ello plantear una contradicción con el paradigma ilustrado. Para el caso que nos ocupa, el topos funcionó como dispositivo simbólico de la rivalidad entre potencias ultramarinas, mediante el cual los viajeros ingleses intentaron desacreditar a sus predecesores que sirvieron a la corona castellana. Los ingleses negaron la cualidad de gigantes para los habitantes de la región del Estrecho, pero en ello no imperó tanto una pulsión por lo real como la reivindicación de sus travesías. ${ }^{33}$

Al igual que como ocurrió con los viajeros del primer cruce transoceánico, la caracterización barbárica de los "patagones" se correspondió con experiencias de contacto violentas derivadas de la resistencia local. Pero lo "monstruoso" de los habitantes fueguinos no descansaba en sus características corporales o en una presunta estatura superior, sino en sus hábitos, especialmente los guerreros. Fletcher descartó el gigantismo en una crítica mordaz a los primeros navegantes del Estrecho:

\footnotetext{
33 Retomando la propuesta de Simón Gallegos Gabilondo, los discursos sobre la "especie" americana no son vistos por su cualidad de representar lo real porque, como él lo entiende, este es también un concepto histórico. La ambigüedad y lo imaginario son propios del discurso literario y también del discurso del saber (Gallegos Gabilondo, 2018: 195).
} 
"Magallanes no fue del todo falaz en llamarlos gigantes, porque ellos generalmente difieren de los hombres comunes, tanto en estatura, robustez y fuerza del cuerpo, como así también en lo espantoso de su voz. Pero ellos no son nada monstruosos o del tipo de los gigantes, como se ha dicho, habiendo algunos ingleses tan altos como el más alto que nosotros pudimos ver. Pero tal vez los españoles no pensaron que alguna vez un inglés podría llegar hasta allí para contradecirlos, y por ello pudieron presumir tales mentiras: los dichos patagones [...] son de siete pies y medio, para describir al más alto entre ellos" (Fletcher, 1628: 28).

En cuanto a la expedición de Cavendish, Hues limitó su descripción como "salvajes de altura razonable" (N. H., 1589: 810), mientras Pretty los consideró sencillamente "comedores de hombres" (Pretty, 1600: 807). Pero los testimonios del viaje de Drake muestran una preocupación por comprender el origen del mito de los gigantes. Cliffe coincidió con la visión de Fletcher al concluir que el mito había sido alimentado por la pretensión de los españoles de "abusar del mundo":

"esos hombres no son de la estatura que los españoles reportan, sino que son de la altura de los ingleses y he visto en Inglaterra hombres más altos que lo que pude ver de cualquiera de ellos. Pero tal vez los españoles no pensaron que algún inglés podría haber ido hasta allí tan pronto para desaprobarlos en esta y otras muchas mentiras notorias, por lo tanto, presumen con audacia para abusar del mundo" (Cliffe, 1600: 751-752).

Un contrapunto evidente respecto a la condición de "gigantes" aparece en el texto de Nuno da Silva, el "conocedor cautivo" (Voigt, 2009: 255). Contrariamente a Fletcher y a Cliffe, da Silva concibió a los habitantes fueguinos como "gente grande y bien formada, y fuertes y altos en estatura" (da Silva, 1600: 743). Esta apreciación fue confirmada por el piloto portugués en su alegato de mayo de 1579. Da Silva recuerda que la zona del Estrecho de Magallanes "estaba poblada de indios cubiertos de pieles y con sus arcos, y que los vestidos le llegaban hasta las rodillas, y la mitad de los braços descubiertos; en las cabecas (sic) no trahian cosa alguna y que era gente bien dispuesta y alta" (da Silva, 1579a: fol. 21).

Sarmiento de Gamboa en 1578 (antes de su servicio en el Estrecho) coincide en presentar a los nativos del Estrecho de Magallanes como "gente muy alta" o "gentes muy crescidas" (Sarmiento de Gamboa, 1889 [1578]: 436), haciéndose eco de los testimonios recogidos por habitantes de la costa chilena tomados prisioneros por Drake y liberados después de haber atacado el puerto del Callao. Tomé Hernández, un sobreviviente de la Ciudad del Rey Don Felipe 
rescatado por Cavendish, también se refirió a los "indios agigantados" (Hernández, 1768: IX) de las costas del Estrecho de Magallanes.

Hernández retoma una escena ya descripta por el cronista Francisco López de Gómara (1552) ${ }^{34}$ al mencionar que un líder indígena "se metió por la boca una flecha, y lastimándose con ella, echó alguna sangre por la boca, se untó con ella los pechos airadamente" a modo de afrenta a Sarmiento de Gamboa. Hernández atribuyó el mencionado hábito al hecho de que "esos Indios eran hechiceros, y les engañaba el Diablo" (Hernández, 1762: X). Pedro Sarmiento de Gamboa repitió la fórmula de los nativos "devoradores de flechas" en la "Relación hecha por Pedro Sarmiento a Su Majestad sobre lo sucedido en el Estrecho cuando allí se quedó y fundó dos ciudades" (1584). Allí señaló que "uno dellos, o por braveza o por fiesta o por sacrificio que hiciese al Demonio, se tragó por la boca una flecha casi de una vara de largo, toda hasta las plumas, y la volvió a sacar llena de sangre". ${ }^{35}$

La representación del fueguino introduciéndose una flecha hasta la garganta fue popularizada en imagen por de Bry en una alegoría del viaje de Magallanes (Americae, vol. 4) y por Levinus Hulsius en la sección sur de su Nova et exacta delineatio Americae, de 1602. A partir de la difusión gráfica de este motivo, la idea de barbarie de los habitantes del Estrecho trascendió su impronta ibérica y se popularizó en todo el viejo continente, mientras los textos de los viajeros ingleses hicieron lo propio sin aludir siquiera al espantoso hábito, sino insistiendo en la ferocidad y la traición.

En cualquier caso, la principal disputa en las representaciones de los nativos gravitó en torno a su condición de gigantes. Las aseveraciones de da Silva, Hernández y Sarmiento de Gamboa contrastan inequívocamente con las objeciones de los testigos ingleses, quienes tomaron la figura del gigante del texto de Pigafetta, ${ }^{36}$ para desacreditar a los españoles en su pretensión de gobernar sobre territorios poblados por seres fantásticos, a la vez que presentaron sus testimonios como prueba de su presencia clandestina pero implacable en territorios poco o mal custodiados por España en el extremo sur del continente americano.

\footnotetext{
34 "Metían y sacábanse por el garguero una flecha para espantar a los extranjeros, a lo que mostraban, aunque algunos dicen que lo usan para vomitar estando hartos..." (López de Gómara, 1979: I-138).

${ }^{35}$ Citado en Benites (2004: 217).

36 Según testificó da Silva en Nueva España, el capitán inglés llevaba con él tres libros de navegación, uno "en françes [,] otro en yngles [,] y el otro hera el descubrimiento de Magallanes no se save en qué lengua". AHN (Inquisición, libro 1048, fol. 5 v.). Citado en Castro Morales (2013: 1).
} 


\section{Poder nominativo}

Bien sabido es que la proposición de nombres para los territorios desconocidos son dispositivos de dominación, en la medida en que señalan la impronta de sus descubridores, tanto por el uso de nombres propios como, indirectamente, por la lengua de origen de quienes lo proponen. Una importante serie cartográfica se hizo eco de la porción más austral del continente, a la que involuntariamente llegó Drake por un fuerte temporal una vez que atravesó el Estrecho. De los tres barcos de la compañía que lograron llegar al Pacífico, uno desapareció (el Marigold) y el otro (el Elizabeth) logró volver por el mismo canal rumbo a Inglaterra. El Golden Hind (nuevo nombre otorgado al Pellican, una vez superado el cruce), con cerca de ochenta hombres, fue arrastrado hasta el sur de Tierra del Fuego, lo que convirtió a Drake en el "descubridor de la insularidad fueguina" (Martinic, 1998), rompiendo así con la larga tradición que consideraba a la mencionada isla como la península de un inmenso territorio austral: la Tierra Austral Incógnita. ${ }^{37}$

A una de las islas donde hicieron aguada nombraron Elizabeth, lo cual constituye un claro posicionamiento de la autoridad inglesa del descubrimiento. La única copia que se conserva del perdido relato original de Fletcher contiene confiables reproducciones de sus dibujos. ${ }^{38}$ Entre ellos, un boceto de la mencionada isla con su fuente de agua dulce (Figura 1) y un mapa invertido que pone en perspectiva el extremo sur de América, presentado a la isla Elizabeth como la culminación de un territorio definido de forma provocativa como "Terra australis bene cognita" (Figura 2). La novedad de la geografía austral circuló celosamente en mapas manuscritos que identifican la isla y marcan una distancia entre esta y un posible continente austral. El más representativo es el mapamundi "Veraz descripción de la expedición náutica del inglés Francis Drake" (c. 1587) de la Mellon Collection del Yale Center for British Art, que además de los elementos señalados incluye el trazo del recorrido de Drake y una bandera inglesa en Elizabeth Island (Figura 3).

\footnotetext{
37 La intervención del descubrimiento de Drake en el conocimiento geográfico queda ejemplificada en un ejemplar del Theatrum Orbis Terrarum de Abraham Ortelius (Amberes, 1579 [1570]). conservado en la British Library. Allí se agregó al impreso de la geografía de la "Terra Australis Nondum Cognita" la ruta de Drake y una nota del descubrimiento de la Isla Elizabeth.

38 Se trata de una copia parcial (que cubre el viaje hasta la Isla Mocha) realizada en 1677 por John Conyers, "farmacólogo" de Londres, y se encuentra en la British Library (Sloane MS 61). Aunque las imágenes son copias de tercera mano, dado que Fletcher reprodujo los bocetos y mapas elaborados por el propio Drake y su primo John Drake, su fidelidad ha sido ponderada por la especialista Helen Wallis (1984: 127). El copista se jactó de su exactitud y agregó notas en los casos en que modificó el tamaño de las imágenes.
} 


\section{Figura 1}

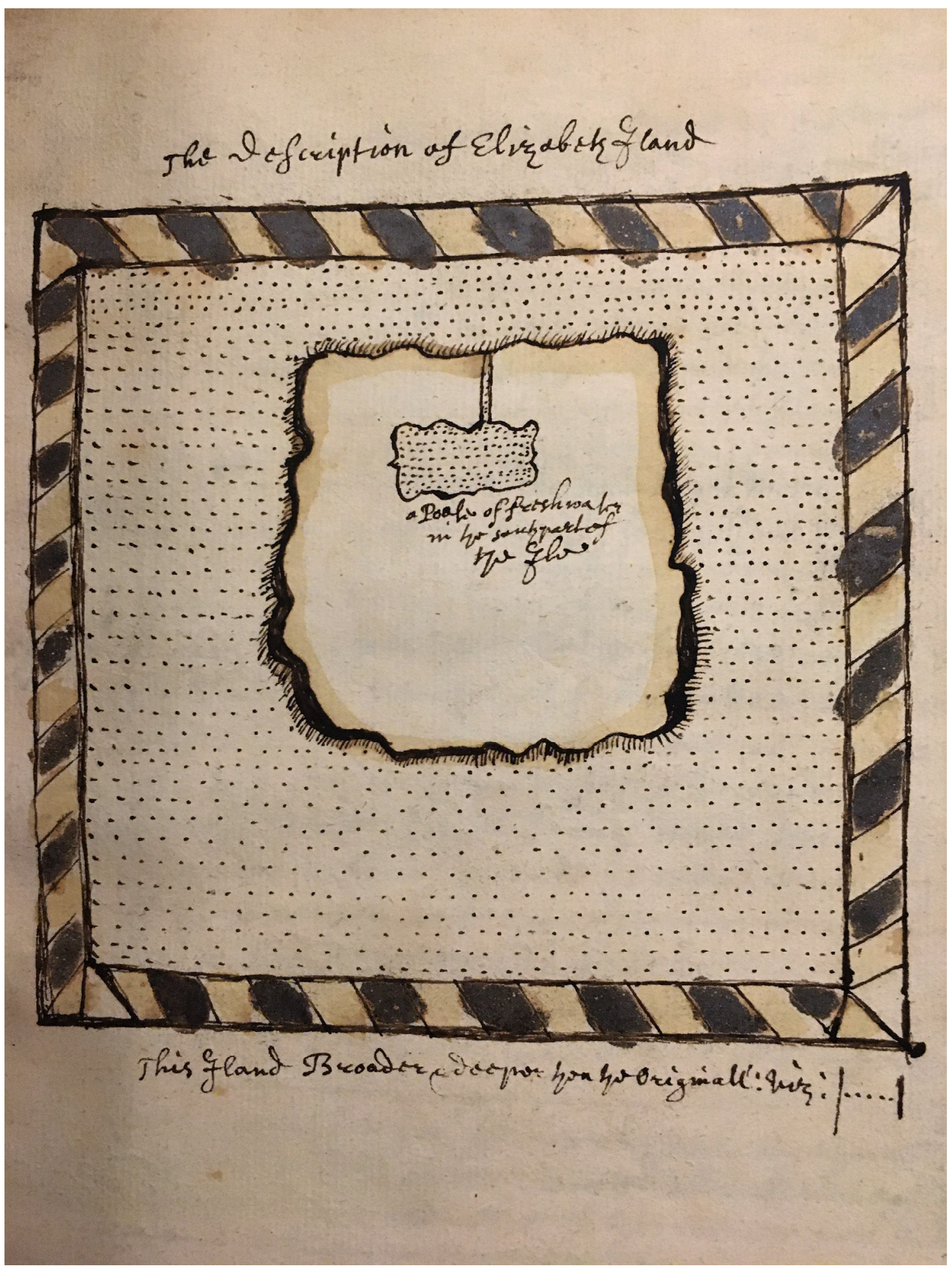

"Descripción de la Isla Elizabeth". Copia de John Conyers (1677) del manuscrito original de Francis Fletcher (British Library, Sloane MS 61, fol. 39r.). Fotografiado por la autora por cortesía de British Library. 


\section{Figura 2}

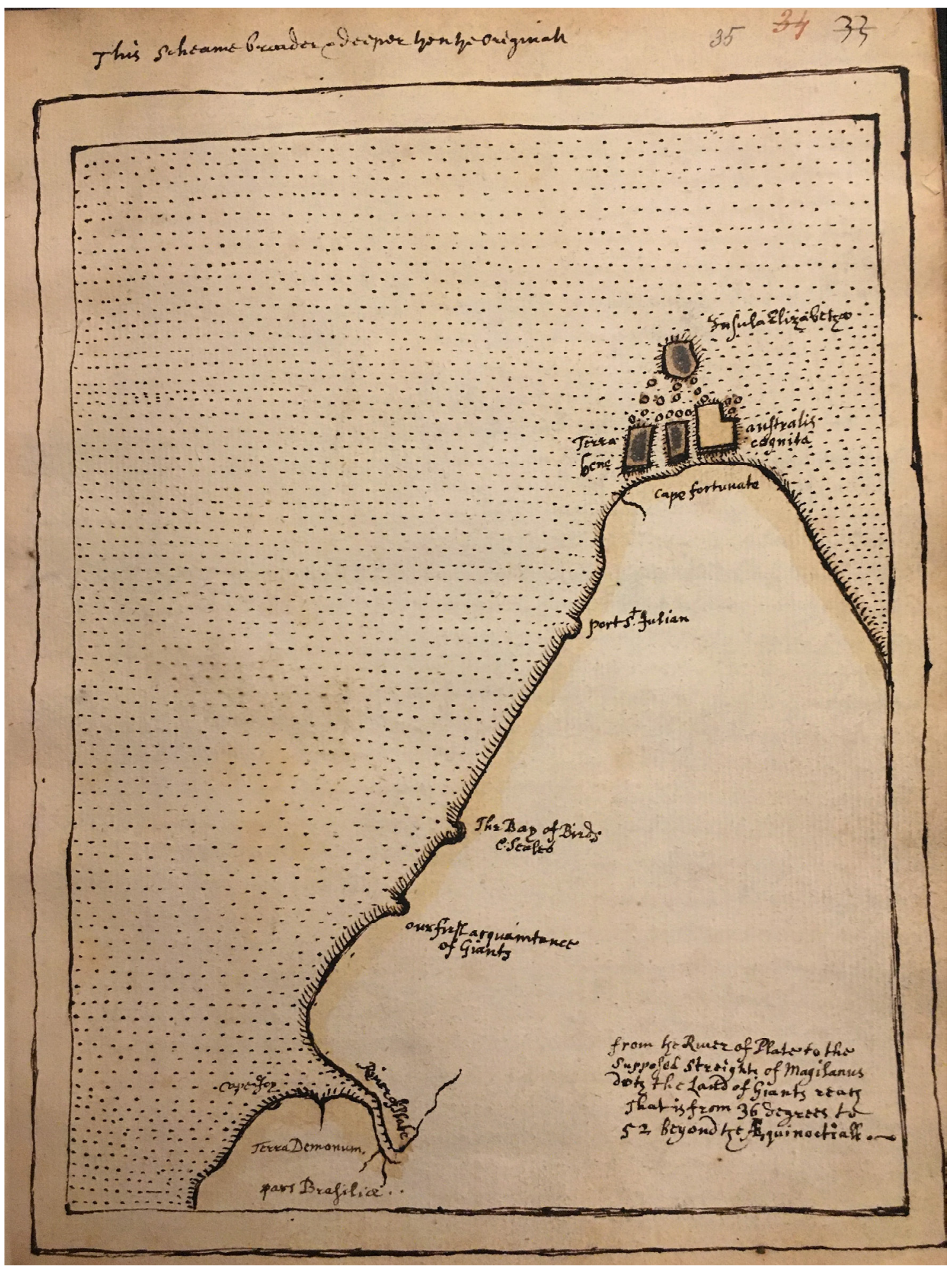

Mapa del extremo sur de la Patagonia. Copia de John Conyers (1677) del manuscrito original de Francis Fletcher (British Library, Sloane MS 61, fol. 35r.). Fotografiado por la autora por cortesía de British Library. 


\section{Figura 3}

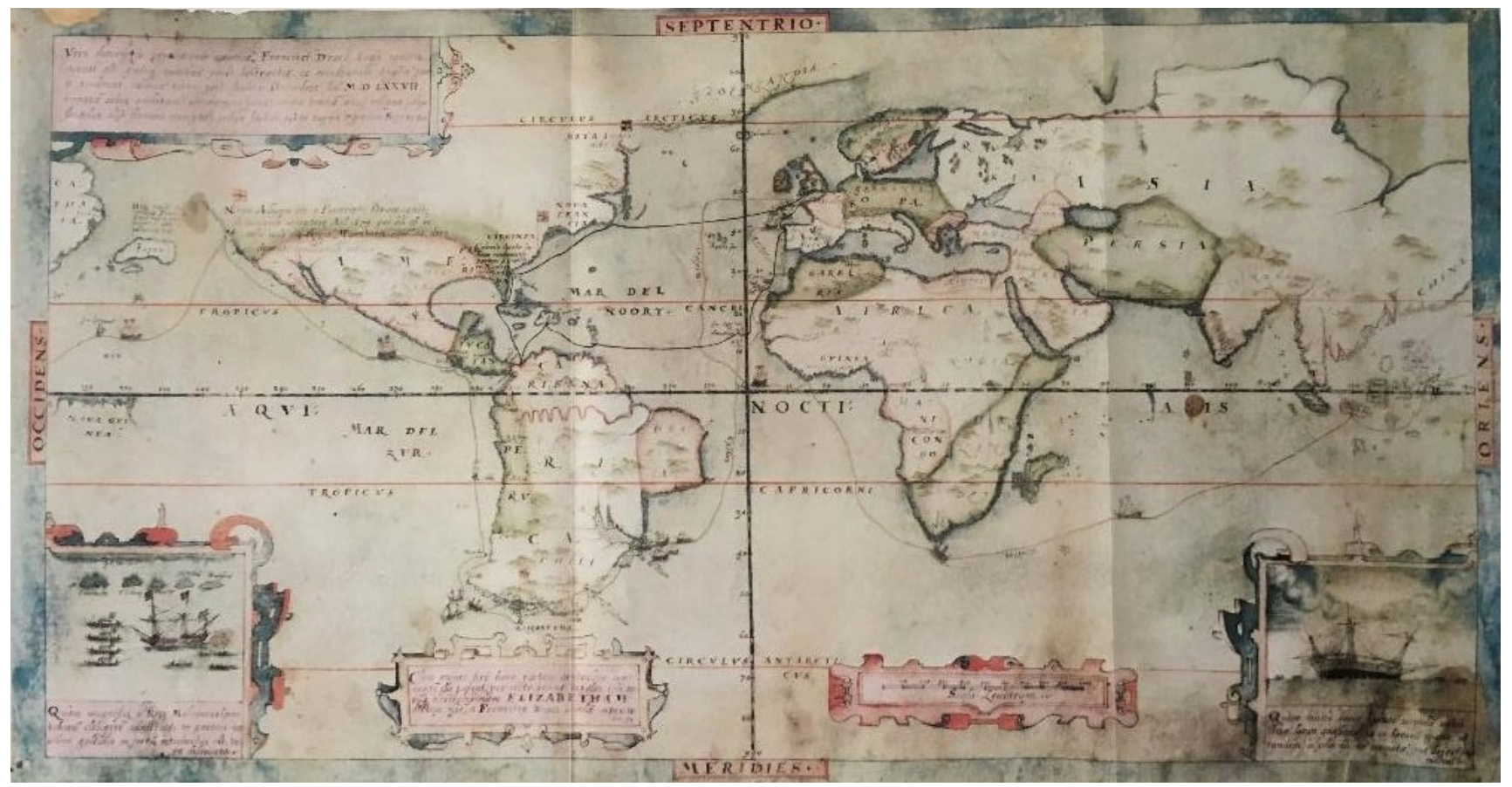

Vera descriptio expeditionis nauticae Francisci Draci Angli... Mapa manuscrito del viaje de circunnavegación de Francis Drake (c. 1587). Yale Center for British Art, Paul Mellon Collection.

Figura 3 Bis

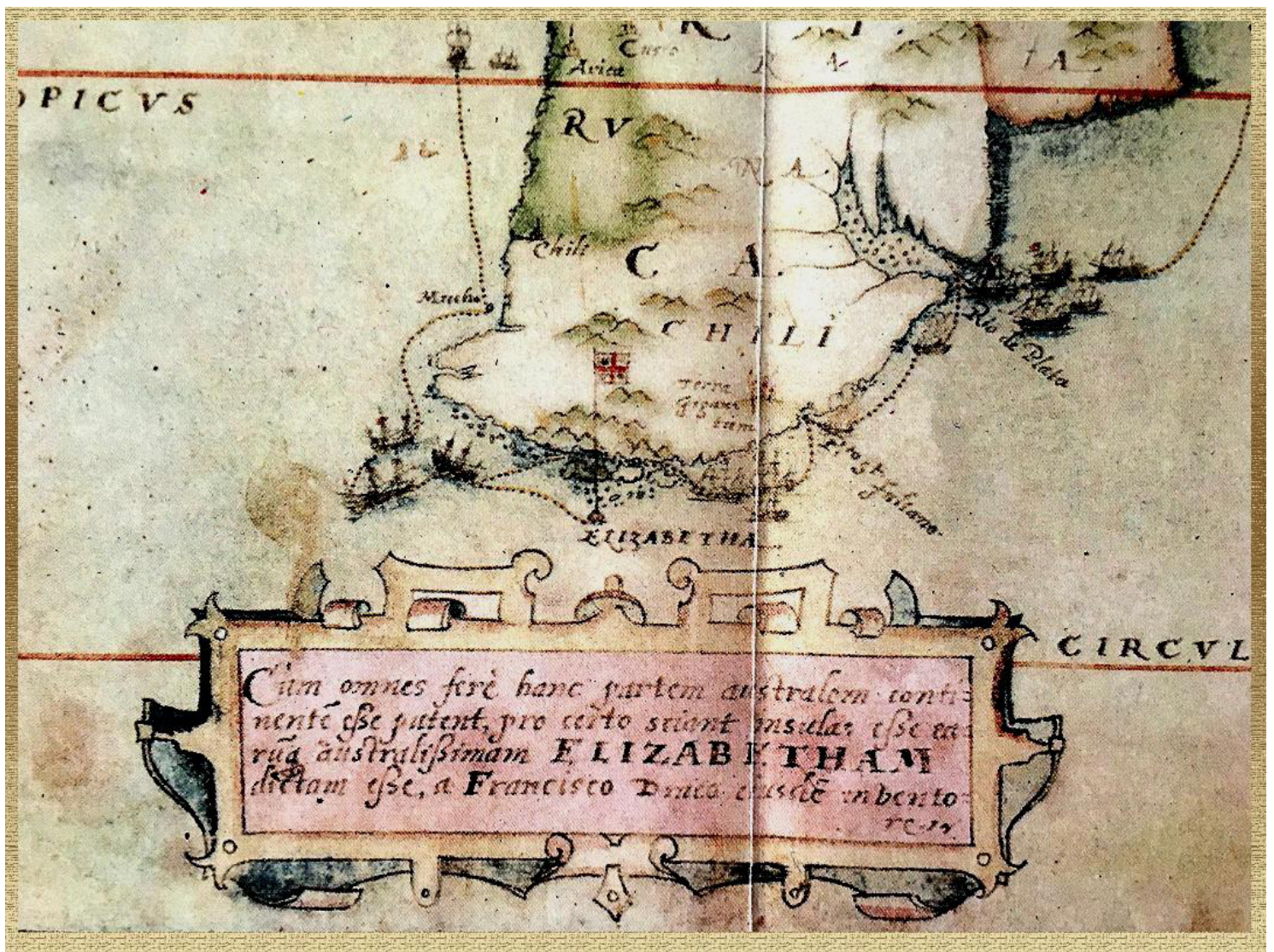

Vera descriptio... (detalle) 
El estallido del conflicto (o su inminencia) entre España e Inglaterra propició la publicación de los mapas de la travesía de Drake. Hakluyt incluyó una versión grabada por Philipp Galle en su edición en latín de Pedro Mártir, De Orbe Novo (París, 1587) (Figura 4) ${ }^{39}$ y Emery Molyneux imprimió el primer globo terrestre realizado por un inglés, en 1592, tan famoso como para ser aludido en The Comedy of Errors (III.ii) por William Shakespeare (Wallis, 1951: 275), en donde se describe a una moza de cocina como "esférica como un globo" en la que se "podría marcar los países sobre ella" (Shakespeare, 1965 [c. 1594]: 75).

\section{Figura 4}

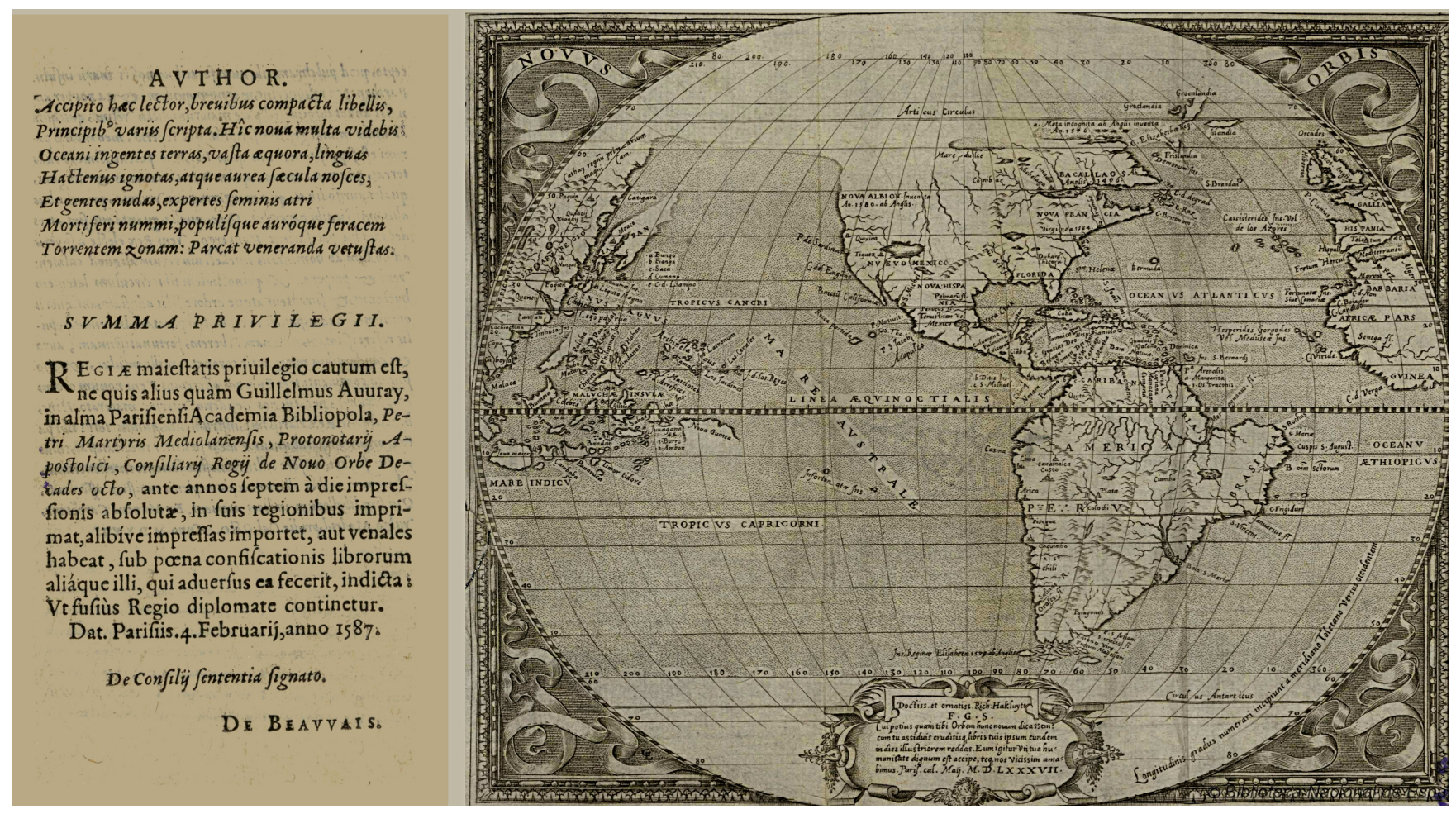

"Novus Orbis", en De Orbe Novo. Petri Martyris Anglerii Mediolanensis, protonotarij, E Caroli Quinti senatoris decades octo... Labore et industria Richard Haklvyti, Paris: Guillaume Auvray, 1587.

Si hubo un legado perdurable del paso de Cavendish por el Estrecho de Magallanes ese fue su impronta nominativa, o lo que Marta Penhos ha denominado el acto de "poner nombre al fracaso" (2018: 95). Los viajeros que acompañaron a Cavendish dejaron en evidencia la calamitosa situación en la que se hallaban los dos pueblos fortificados españoles, Nombre de Jesús y Ciudad del Rey Don Felipe, los cuales habían sido fundados por Pedro

39 Como sostuvo Mateo Martinic, este mapa "no sólo el archipiélago magallánico adquiere proporciones más ajustadas, sino que además el continente asume una forma terminal aguzada mucho más aproximada a su verdadera conformación que la presentada en las anteriores cartas" (Martinic, 1999: 68). 
Sarmiento de Gamboa en 1584 con el propósito de proteger al Estrecho de las incursiones enemigas en el Estrecho. A la Ciudad del Rey Don Felipe Cavendish rebautizó Port Famine [Puerto Hambre], luego de atestiguar que estaba habitada por apenas una veintena de sobrevivientes "miserablemente hambrientos" que habían "tomado la determinación de viajar hasta el Río de la Plata" (Pretty, 1600: 806). ${ }^{40}$ Uno de ellos, el ya referido Tomé Hernández, fue rescatado por los ingleses y se escapó de ellos al llegar a la costa de Chile. Cavendish mandó a cargar en sus barcos seis piezas de artillería de la extenuada guarnición española y se retiró con prisa de ese "lugar infecto" (N. H., 1589: 810). Según Pretty, la Ciudad del Rey Don Felipe estaba

“muy bien diseñada y emplazada en el mejor lugar del estrecho por madera y agua. Ellos mismos [los españoles] habían levantado sus iglesias y tenían leyes muy severas, para lo cual habían montado una horca, en la que habían ejecutado a algún miembro de su compañía." (Pretty, 1600: 806). ${ }^{41}$

Pero la Ciudad del Rey Don Felipe no contaba con recursos para alimentar a sus habitantes y "sus provisiones se agotaron al punto que murieron como perros en sus casas y con sus ropas, como los encontramos cuando llegamos, hasta que al final el pueblo estaba asombrosamente contaminado con el olor y el sabor de la gente muerta" (Pretty, 1600: 806). ${ }^{42}$ Puerto Hambre se convirtió así en ese "sitio de carencias extremas contra las que irían a estrellarse una y otra vez las naves europeas que llegaron hasta ahí" (Penhos, 2018: 97), al punto tal que el topónimo fue adoptado sin cuestionamientos por los hombres de la expedición del Beagle, en las décadas de 1820-1830. Al hambre fatal de los españoles, tantas veces lamentada por los cronistas españoles, Hues contrapuso la abundancia de carne de gaviota, pingüino y focas de Puerto Deseado, mientras experimentó que la "Isla Pingüino" era capaz de proveer "trescientas toneladas de pingüino" (Hues, 1589: 809). De esta manera, sugería a sus lectores ingleses una estrategia para afrontar el paso por el Estrecho.

\footnotetext{
${ }^{40}$ Pretty informa que "solo quedaban vivas 23 personas, de las cuales dos eran mujeres, que era lo que quedaba de cuatrocientos" (Pretty, 1600: 806).

${ }^{41}$ Según el testimonio de Tomé Hernández, Sarmiento de Gamboa había mandado ejecutar a cuatro colonos de Ciudad del Rey Don Felipe que habían conspirado contra él y planeado volver a Brasil "porque ya no podían sufrir aquella vida" (Hernández, 1768: apéndice-xii).

${ }^{42}$ En la traducción de la edición de Pedro Sarmiento de Gamboa ,el pasaje continúa así: "los que conservaron la vida se decidieron a enterrar las cosas que tenían allí en el pueblo y seguir por la ribera del mar en busca de algún alimento que les salvara de morir de hambre, sin llevar consigo nada más que el arcabuz y su provisión, el que era capaz de llevarla (algunos no eran capaces de llevarla por su debilidad), y así vivieron por espacio de un año y más con raíces, hojas y en ocasiones alguna ave silvestre que lograban matar con sus armas" (1950: II-368).
} 
El poder nominativo de la expedición de Cavendish también se evidencia en el topónimo Puerto Deseado, "de acuerdo con el nombre de nuestro barco" (N. H., 1589: 809), el Desire. Cavendish también dio nombre a Pengwin Island (Martinic, 2012: 10), mientras que los sitios marcados en el mapa de Fitz Roy (1839) como Execution Island e Isle of True Justice, en las cercanías del Puerto San Julián, rememoraban la ejecución de Doughty ordenada por Drake. Este topónimo fue incorporado al momento de la edición del texto de Fletcher, donde constaba queque el juicio a Doughty se había llevado a cabo "en una de las islas de ese puerto, la cual fue nombrada más tarde isla de la Verdadera justicia y juicio" (Fletcher 1628: 31). ${ }^{43}$ Así, la irrupción de los ingleses por el Estrecho de Magallanes, en sus dos ocasiones, quedó sellada en la historia de las navegaciones, tanto en los textos de sus testigos como en los mapas que se elaboraron posteriormente.

\section{La alteridad en el espejo}

Los testimonios analizados sobre los viajes de circunnavegación de Francis Drake y Thomas Cavendish se inscriben en el inicio de una genealogía de afirmación del imperialismo inglés, en el que el editor Richard Hakluyt cumplió un rol central. En su paso por el Estrecho de Magallanes, los viajeros ejercieron un trato hostil con los indígenas, a quienes se consideraban bárbaros como consecuencia de sus contactos previos con los españoles. Así es que Fletcher afirmó que "es cierto que las crueldades perpetradas por los españoles los hicieron más monstruosos, más en mentalidad y en costumbres que en lo que son corporalmente, y más inhospitalarios para tratar con extranjeros" (Fletcher, 1628: 28).

La denuncia de las crueldades cometidas contra los denominados "patagones" es constitutiva de un programa de expansión ultramarina que, por entonces, apuntaba a un trato pacífico con los indígenas, basado en relaciones comerciales. La vocación religiosa del capellán de Drake alimentó probablemente su inquietud por la salvación de las vidas y las almas de los indígenas. Es así como, en la construcción de una otredad "monstruosa" de aspectos políticos (la falta de hospitalidad con los extranjeros) y culturales (mentalidad y costumbres), Fletcher exaltó las cualidades negativas de estos habitantes, derivadas todas ellas del contacto con los españoles. Al desacreditar el aspecto fisonómico de un supuesto gigantismo, el testigo también se

\footnotetext{
${ }^{43}$ En cursiva en el original. Los hombres de Drake encontraron los restos de la horca y de los huesos de las víctimas ajusticiadas por Magallanes también en la zona de San Julián (Fletcher, 1628: 33). La controversia sobre el ajusticiamiento de Doughty se mantuvo en la memoria de los viajeros a la América Meridional, al punto que Fitz Roy intervino en su diario de viaje del Beagle (1839) al topónimo True Justice, agregando entre paréntesis: “or injustice?" (Penhos, 2018: 100).
} 
presentaba como autoridad de la representación de ese espacio americano tan esquivo como incitante. De este modo, la representación de ese otro fueguino operaba, como un tiro por elevación, en denuncia y programa colonial. ${ }^{44}$

Distinto es el caso de los testigos de la expedición de Cavendish, Hues y Pretty, dos gentilhombres que exaltaron el aspecto militar y mostraron escaso interés por un eventual dominio colonial inglés sobre los territorios recorridos y sus habitantes. Un pasaje bastante conocido de Pretty condensa una visión negativa tanto de la geografía como de los habitantes: la primera indómita, los segundos salvajes. En su trayecto por el Estrecho

“No vimos ninguna otra tierra que no fueran rocas escarpadas y monstruosas, colinas altas y montañas. En ese río hay gran cantidad de salvajes que nosotros vimos y con los que conferenciamos. Ellos son comedores de hombres y también se alimentan de carne cruda y otra comida asquerosa, y antes habían asaltado a los españoles"' (Pretty, 1600: 806-807).

Sin indagar las causas del mencionado ataque a los españoles, cuya información podría haber provisto Tomé Hernández, Pretty enfatiza la condición traidora de los indígenas. Cuando se encontraron con ellos, armados con cuchillos y dardos de metal, "hicieron todo lo posible para atraernos río arriba con el propósito de traicionarnos, lo cual fue descubierto por nuestro general, quien nos mandó a dispararles con nuestros arcabuces, por lo que matamos a muchos de ellos" (Pretty, 1600: 807). La intuición de Cavendish respecto de una posible traición fue suficiente para desatar la matanza, que no dejó en este texto, ni en el de N. H., registro de una inquietud sobre las trayectorias que pudiesen explicar la reticencia de los indígenas a tratar con los recién llegados.

El sello editorial de Bry colaboró con la difusión de los viajes de circunnavegación ingleses, aunque allí el espacio patagónico tuvo una cobertura marginal. El paso de Drake por el Estrecho no cuenta con una alusión en imagen, mientras que el contacto con los miwok de la zona de California se exhibe con generosidad, enseñando ciertas costumbres y la dignidad de los líderes locales (de Bry, 1599: plancha V). De la experiencia de Cavendish solo se retrata una matanza de lobos marinos y en segundo plano una escena de

\footnotetext{
${ }^{44}$ Esta interpretación queda respaldada al considerar el caso contrario de la representación de los miwok, habitantes de Nueva Albión, fundada por Drake en la costa de la actual California en junio de 1579. Fletcher (o su editor) le destina más espacio a la descripción de esos posibles súbditos de la corona inglesa, mostrándolos como habitantes dóciles, amistosos y a la vez poseedores de un gobierno propio y con atributos de autoridad homologables a los de los europeos (López Palmero, 2020). La ventaja de la primicia fue explotada por Fletcher, del mismo modo que, según su propia denuncia, habían hecho los hombres de Magallanes en el Estrecho, exaltando cualidades que hicieran popular la experiencia colonial.
} 
enfrentamiento con los indígenas, cuyas dos víctimas resultantes son dos ingleses atravesados por flechas (de Bry, 1599: plancha X) (Figura 5).

\section{Figura 5}

\section{$\mathrm{X}$. \\ QVOMODO DN. CANDISCH. \\ IN QVADAM INSVLA MVLTOS CA- nes marinos varij generisinuenerit.}
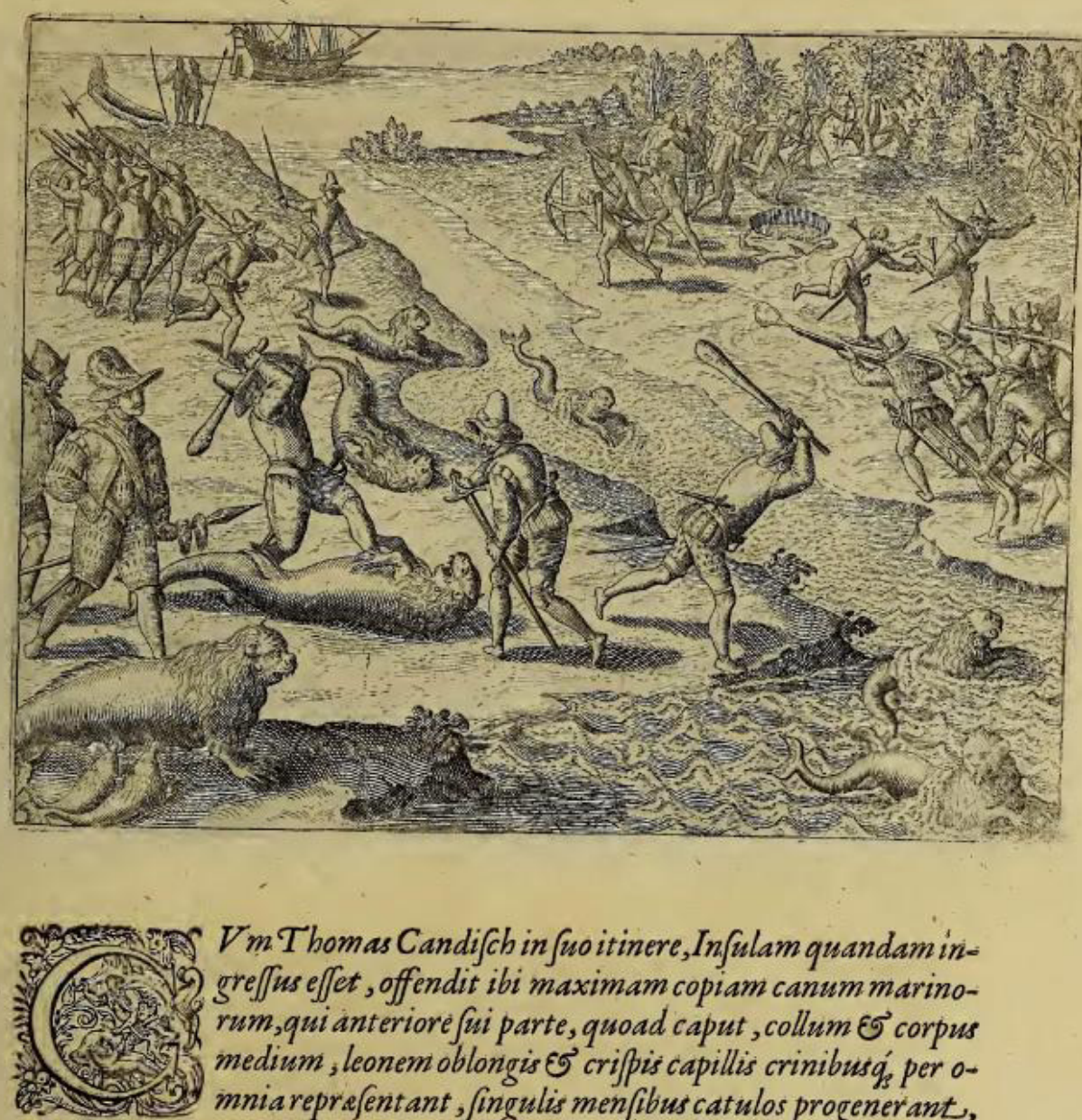

T $T$ homas Candifch in fwo itinere, Infulam quandam ingreffus effet, offendit ibi maximam copiam canum marinorum, qui anteriore fui parte, quoad caput, collum E corpus medium, leonem oblongis E crifpis capillis crinibusq́, per omnia reprefentant, ingulis menfibus catulos progenerant, quos lacte fwo enutriunt. Hos canes interficere nullis armis potuimus, donec fuftibus capita ipforum percuteremus: 2 uin etiam tanti roboris erant, vt nofrum tres vel quatuor vnum fuperare E interficere vix poffemus. Carnem habent bonicibi, que veruecinam fapore refert. In hac regione duo ex noftris, nimirum nauta cum alio quopiam, ad fontem aliquädo ibi à nof tris effo fum iwerunt, vt indufia fua lawarent: Hos ex improwifo Indiani opprefferunt, छ" vnum quidem in humero, alterum vero in genu vulnerârunt, fed Indiant tamen iffiftatim a fuperuenientibus Anglis reliquis in fugam verff funt:

$$
\text { c } 3
$$

“Quomodo DN. Candisch, in quadam insula multos canes marinos varij generis inuenerit". En Théodore de Bry (ed.) (1599). Americae Pars VIII. Francofurti ad Moenum: sumptibus Theodorici de Bry, viduae et filiorum [per Matthaeum Becker]. 
Más allá de la economía de recursos que habría caracterizado al octavo volumen de los herederos de Théodore de Bry a poco de su fallecimiento (si se considera que este había preparado las planchas), es de suponer que hubo una deliberada intención de sortear la descripción visual de los habitantes del Estrecho, probablemente debido a la débil expectativa de dominio efectivo. Por el contrario, la imagen de la cacería de Cavendish habría resultado útil, al señalar los recursos disponibles para la alimentación, ${ }^{45}$ de aquellos viajeros que intentaran contribuir en un futuro a la gloria de la navegación inglesa.

\section{Reflexiones finales}

Hasta aquí, el análisis de los primeros relatos publicados sobre los viajes de circunnavegación de Francis Drake y Thomas Cavendish permite considerar las apropiaciones simbólicas tendientes a afirmar el incipiente imperialismo inglés en ultramar. Los topónimos, que pasaron a configurar la representación geográfica del Estrecho de Magallanes por los siglos venideros, fueron parte de ese proceso y tuvieron la capacidad, como sostiene Carla Lois, de "crear paisajes" (2010: 319). Paisajes o representaciones imaginarias de un espacio indómito para el que los ingleses, a diferencia de los frustrados españoles, se consideraban preparados para recorrer, explotar y eventualmente dominar.

La representación negativa de la otredad de los habitantes fueguinos estuvo condicionada por un contacto hostil, aunque con sensibles diferencias. Los viajeros de Drake, especialmente el capellán Fletcher, mostraron cierta inquietud por la fisonomía y por la actitud insumisa de los habitantes nativos, lo cual les dio margen para desacreditar a los primeros descubridores españoles y también criticar expresamente las crueldades cometidas por ellos. Ese ejercicio probablemente estimuló la curiosidad y moldeó cierta visión sobre los indígenas. Los viajeros de Cavendish solo se aferraron a argumentos de estrategia militar: adelantarse al ataque seguro de los traidores locales. Un despliegue más desenfadado de violencia ya sea contra los indígenas o contra los españoles, fue habilitado por el conflicto abierto entre las coronas rivales, por lo que la demostración de fuerza adquirió un valor en sí mismo, que los textos transmitieron para regocijo y orgullo de los lectores ingleses.

Buenos Aires, febrero de 2020

\footnotetext{
45 Desde luego, la información sobre los recursos alimenticios fue apreciada por los viajeros de Drake, como lo muestra la fascinación de Fletcher por los pingüinos, de los que dice que se mataron en un día "no menos de 3000" (Fletcher, 1628: 35) y la estimación de da Silva sobre los lobos marinos y patos, de los que se habrían tomado "más de dos mil y no se echaban de ver según había muchos". Declaración de Nuno da Silva ante la Inquisición de Nueva España, 1579. En AGN [México] (Inquisición, 1579, volumen 85, expediente 13 (folios 84r. a 94v.), fol. 91v.) Citado en Martínez Pérez (2016: 100).
} 


\section{Fuentes inéditas}

Archivo General de Indias, Patronato 266 R 17, nº 3.

Archivo General de Simancas, Estado-Legajo núm. 0817.

British Library, Sloane MS 61: "Reverend Francis Fletcher: Narrative, as eyewitness..." (copia, 1677).

Da Silva, Nuno (1579a). "Relación del viaje del cosario yngles que dio el piloto Nuno de Silva ante su excelencia del virrey de México a 20 de mayo de 79 y esta no la dio el tan desmenuçada sino que como se le iva preguntando respondia" (copia). En "Memoria de la Costa Rica del Mar del Norte (With Three other Narratives)", serie manuscrita de la Colección Kraus de la Biblioteca del Congreso de los Estados Unidos, (folios 20 a 24). https://memory.loc.gov/cgi$\underline{\text { bin/ampage? collid }=\mathrm{rbdk} \& \text { fileName }=\mathrm{d} 001 / \mathrm{rbdkd001} . \mathrm{db} \& \mathrm{recNum}=19}$

(consultado el 26/12/2019)

\section{Fuentes impresas}

Cavendish, Thomas (1589). "A letter of Master Thomas Candish to the right honorable the Lord Chamberlaine, one of her Maiesties most honorable privie Counsell, touching the successe of his voyage about the world", en Richard Hakluyt (ed.) (1589), The Principall Navigations, voiages and discoveries of the English Nation, made by Sea or over Land, to the most remote and farthest distant Quarters of the earth at any time within the compasse of these 1500 yeeres: Devided into three severall parts, according to the positions of the Regions whereunto they were directed, London: George Bishop and Ralph Newberie, p. 808.

Cliffe, Edward (1600). "The voyage of M. John Winter into the South sea by the stright of Magellan, in comfort with M. Francis Drake, begun in the yeere 1577...", en Hakluyt, Richard (ed.), The Principal navigations, voyages, trafiques and discoveries of the English Nation, made by Sea or overland, to the remote and farthest distant quarters of the earth, at any time within the compasse of these 1600 yeeres: divided into three severall volumes: according to the position of the regions, whereunto they were directed, 3 vols., London: George Bishop, Ralph Newberie y Robert Barker, vol. 3, pp. 748-753.

Da Silva, Nuno (1600). "The relation of a voyage made by a pilot called Nuno da Silva...", en Hakluyt, Richard (ed.), The Principal navigations, voyages, trafiques and discoveries of the English Nation, made by Sea or over-Land, to the remote and farthest distant quarters of the earth, at any time within the compasse of these 1600 yeeres: divided into three severall volumes: according to the position of the regions, whereunto they were directed, 3 vols., London: George Bishop, Ralph Newberie, and Robert Barker, vol. 3, pp. 742-748. 
Da Silva, Nuno (1579b). "Log-book”, en Nutall, Zelia (ed.) (1914), New Light on Drake. A Collection of Documents Relating to his Voyage of Circumnavigation, 15771580, London: Hakluyt Society, pp. 277-295.

De Bry, Théodore (ed.) (1599). Americae Pars VIII, Francofurti ad Moenum: sumptibus Theodorici de Bry, viduae et filiorum [per Matthaeum Becker].

Fletcher, Francis (1628). The World Encompassed by Sir Francis Drake, being his next voyage to that to Nombre de Dios formerly imprinted; Carefull collected out of the notes of Master Francis Fletcher Preacher in this employment, and divers others his followers in the same: Ofered now at last to publique view, both for the honour of the actor, but especially for the stirring up of her sick spirits to benefit their Countrie, and eternize their names by like noble attempts, London: Nicholas Bourne.

Fuensanta del Valle, Marqués de; Rayón, José Sancho y Zabálburu, Francisco de (eds.) (1889). Colección de documentos inéditos para la historia de España, 112 vols., Madrid: M. Ginesta Hermanos, vol. XCIV.

Hakluyt, Richard (ed.) (1589). The Principall Navigations, voiages and discoveries of the English Nation, made by Sea or over Land, to the most remote and farthest distant Quarters of the earth at any time within the compasse of these 1500 yeeres: Devided into three severall parts, according to the positions of the Regions whereunto they were directed, London: George Bishop and Ralph Newberie.

Hakluyt, Richard (ed.) (1600). The Principal Navigations, Voiages and Discoveries of the English Nation, made by Sea or over-Land, to the most remote and farthest distant Quarters of the earth at any time within the compasse of these 1500 yeeres: Divided into three several parts, according to the positions of the Regions whereunto they were directed (3 vols.), vol. 3, London: George Bishop, Ralfe Newberie, and Robert Barker.

[Hakluyt, Richard] (1589). "The famous voyage of Sir Francis Drake into the South Sea, and there hence about the whole Globe of the Earth, begun in the yeere of our Lord, 1577", en The Principall Navigations, Voiages and Discoveries of the English Nation, mad by Sea or over-Land, to the most remote and farthest distant Quarters of the earth at any time within the compasse of these 1500 yeeres: Divided into three several parts, according to the positions of the Regions whereunto they were directed, London: George Bishop and Ralph Newberie, s/p.

Hakluyt, Richard (1877), "Discourse of Western Planting", en Deane, Charles (ed.), History of the State of Maine. Containing a Discourse of Western Planting written in the year 1584 by Richard Hakluyt, Cambridge: Press of John Wilson and Son, pp. 1-167.

H[ues], N [R]. (1589). "The worthy and famous voyage of Master Thomas Candishe made round the globe of the earth, in the space of two yeeres and lesse then two monethes, begun in the yeere 15862", en Hakluyt, Richard (ed.), The Principall Navigations, Voiages and Discoveries of the English Nation, mad by Sea 
or over-Land, to the most remote and farthest distant Quarters of the earth at any time within the compasse of these 1500 yeeres: Divided into three several parts, according to the positions of the Regions whereunto they were directed, London: George Bishop and Ralph Newberie, pp. 809-813.

Hernández, Tomé (1768). "Declaración que de orden del Virréi del Perú D. Francisco de Borja, Príncipe de Esquilache, hizo, ante Escribano, Tomé Hernández, de lo sucedido en las dos Poblaciones Fundadas en el Estrecho de Magallánes por Pedro Sarmiento de Gamboa", en Iriarte, Tomás de (ed.), (1768), Viage al Estrecho de Magallanes por el capitán Pedro Sarmiento de Gambóa, en los años de 1579 y 1580, y noticia de la expedición que después hizo para poblarle, Madrid: Imprenta Real de la Gazeta, "apéndice”, pp. I-XXXII.

La Popelinière, Henri Voisin de (1582). Les Trois Mondes, París: L'Huiller, vol. 3.

López de Gómara, Francisco (1979) [1552]. Historia General de las Indias y Vida de Hernán Cortés. Prólogo y cronología de Jorge Gurría Lacroix, Caracas: Biblioteca Ayacucho.

Lopes Vas (1589). "A very exact and perfect description of the distances from place to place, from the river of Plate, till you come to Pette Guaras, northward, and beginning againe at the river of Plate, till you come to the ende of the Straights of Magellan, Southwards, with the degrees of latitude, wherein every place standeth", en Hakluyt, Richard (ed.), The Principall Navigations, Voiages and Discoveries of the English Nation, mad by Sea or over-Land, to the most remote and farthest distant Quarters of the earth at any time within the compasse of these 1500 yeeres: Divided into three several parts, according to the positions of the Regions whereunto they were directed, London: George Bishop and Ralph Newberie, pp. 803-808.

Pretty, Francis (1600). "The admiral and prosperous voyage of the worshipfull Master Thomas Candish [Cavendish] in the countie of Suffolke Esquire, into the South sea, and from thence round about the circumference of the whole earth, begun in the yeere of our Lord 1586, and finished 1588", en Hakluyt, Richard (ed.), The Principall Navigations, Voiages and Discoveries of the English Nation, made by Sea or over-Land, to the most remote and farthest distant Quarters of the earth at any time within the compasse of these 1500 yeeres: Divided into three several parts, according to the positions of the Regions whereunto they were directed, 3 vols (15981600), vol, 3, London: George Bishop, Ralfe Newberie, and Robert Barker, pp. 803-825.

Pretty, Francis (1910). "Sir Francis Drake's famous voyage round the world", in Eliot, Charles W. (ed.), Voyages and Travels Ancient and Modern, Hardvard Classics vol. 35, New York: Collier \& Son Company, pp. 207-268. Reeditado en New York por Cosimo Classics (2005), pp. 207-236. 
Sarmiento de Gamboa, Pedro (1950). Viajes al Estrecho de Magallanes, 1579-1584. Edición de Ángel Rosenblat, 2 vols., Buenos Aires: Emecé.

Sarmiento de Gamboa, Pedro (1889). "Relación de lo que el cosario Francisco hizo y robó en la costa de Chile y Pirú, y las diligencias que el virey don Francisco de Toledo hizo contra él", en Fuensanta del Valle, Marqués de; Rayón, José Sancho y Zabálburu, Francisco de (eds.) (1889). Colección de documentos inéditos para la historia de España, 112 vols., vol. LXIV, Madrid: M. Ginesta Hermanos, 1842-1896, pp. 432-458.

Shakespeare, William (1965 [c. 1594]). The Comedy of Errors, New York: Signet Classic.

Vaux, William S. W. (ed.) (1854). The World encompassed by Sir Francis Drake, London: Hakluyt Society.

Wright, Irene A. (ed) (1929). Spanish Documents Concerning English Voyages to the Caribbean, 1527-1568, London: Hakluyt Society.

\section{Bibliografía citada}

Andrews, Kenneth R. (1974). "Latin America”, en Quinn, David B. (ed.), The Hakluyt Handbook, 2 vols., London: Hakluyt Society, vol. 1, pp. 234-243.

Augeron, Mickaël (1997). "Coligny et les Espagnols a travers la course (15601572): une politique maritime au service de la Cause protestante", en Acerra, Martine (ed.), Coligny, les Protestants et la mer, Paris: Presses de l'Université de Paris-Sorbonne, pp. 155-176.

Armitage, David (2004 [2000]). The Ideological Origins of the British Empire, Cambridge: Cambridge University Press.

Appleby, John C. (2001 [1998]). “War, Politics, and Colonization, 1558-1625”, en Canny, Nicholas (ed.). The Origins of Empire. British Overseas Enterprise to the Close of the Seventeenth Century. Vol. 1 de "The Oxford History of the British Empire" (5 vols.), Oxford: Oxford University Press, pp. 55-78.

Benites, María Jesús (2004). "Con la lanza y con la pluma". La escritura de Pedro Sarmiento de Gamboa, San Miguel de Tucumán: Facultad de Filosofía y Letras de la Universidad Nacional de Tucumán.

Bueno Jiménez, Alfredo (2016). “El Nuevo Mundo en el imaginario gráfico de los europeos. De Bry, Hulsius, Jacob Van Meurs y Pieter Van der Aa, Revista San Soleil. Estudios de la Imagen, vol. 8, pp. 229-256.

Bueno Jiménez, Alfredo (2013). Hispanoamérica en el imaginario gráfico de los europeos. De Bry y Hulsius. Tesis doctoral por la Universidad de Granada. Edición on-line de la Universidad de Granada, https://hera.ugr.es/tesisugr/23007941.pdf (consultado el 31/12/19). 
Burke, Peter (2002). "Context in context", Common Knowledge, vol. 8, issue 1 (Winter 2002), pp. 152-177.

Canny, Nicholas (2001 [1998]). "The Origins of Empire: An Introduction", en Canny, Nicholas (ed.) The Origins of Empire. British Overseas Enterprise to the Close of the Seventeenth Century. Vol. 1 de "The Oxford History of the British Empire" (5 vols.), Oxford: Oxford University Press, pp. 1-33.

Castro Morales, Belén (2013). "Francis Drake en la Patagonia", Revista de Lengua y Literatura, Universidad Nacional de Comahue, núm. 36, 13 págs. http://revele.uncoma.edu.ar/htdoc/revele/index.php/letras/article/view/94/576 (consultado el 7/1/2020)

Chartier Roger. (2001 [1996]). Escribir las prácticas. Foucault, de Certau, Marin, Buenos Aires: Manantial.

Draper, Benjamin P. (1984). "A Collection of Drake Bibliographic Items, 15691659", en Thrower, Norman (ed.), Sir Francis Drake and the famous voyage, 15771580, Los Angeles: University of California, pp. 173-206.

Elliott, John H. (1972 [1970]). El Viejo y el Nuevo Mundo, 1492-1650, Madrid: Alianza.

Gallegos Gabilondo, Simón (2018). Les Mondes du Voyageur. Une épistémologie de l'exploration (XVI ${ }^{e}-X V I I I^{e}$ siècle), París : Éditions de la Sorbonne.

Games, Alison (2006). "Beyond the Atlantic: English Globetrotters and Transoceanic Connections", en The William and Mary Quarterly, Third Series, vol. 63, n 4 (Oct. 2006), pp. 675-692.

Gill, Crispin (1884). "Drake and Plymouth", en Thrower, Norman (ed.), Sir Francis Drake and the famous voyage, 1577-1580, Los Angeles: University of California, pp.78-89.

Greenhow, Robert (1844). The History of Oregon and California and the Other Territories on the North-West Coast of North America, London: John Murray.

Lane, Kris E. (1998 [1967]). Pillaging the Empire. Piracy in the Americas, 1500-1750, New York: Sharpe.

Lois, Carla (2010). "Paisajes toponímicos. La potencia visual de los topónimos y el imaginario geográfico sobre la Patagonia en la segunda mitad del siglo XIX", en Roque de Oliveira, Francisco y Mendoza Vargas, Héctor (comps.), Mapas de la mitad del mundo. La cartografía y la construcción territorial de los espacios americanos, siglos XVI al XIX, Lisboa: Centro de Estudos Geográficos, Universidade de Lisboa, pp. 317-341.

López Palmero, Malena (2020). “Alteridades confrontadas en los relatos del viaje alrededor del mundo de Francis Drake (1577-1580)", en AAVV, El Renacimiento. La vida cultural europea entre los siglos XIV y XVII, Buenos Aires: 
Editorial de la Facultad de Filosofía y Letras de la Universidad de Buenos Aires. En prensa.

López Palmero, Malena (2016). "Avatares editoriales del viaje de circunnavegación de Francis Drake (1577-1580)", en González Mezquita, María Luz (ed.), Historia Moderna: actores, discursos y prácticas, Mar del Plata: Universidad Nacional de Mar del Plata, pp. 195-200.

Mancall, Peter C. (2007). Hakluyt's Promise. An Elizabethan's Obsession for an English America, New Haven and London: Yale University Press.

Marin, Louis 2009 (1981). “Poder, representación, imagen”, Prismas. Revista de historia intelectual, $\mathrm{n}^{\circ} 13$, pp. 135-153

Martínez, Carolina (2019). Mundos perfectos y extraños en los confines del Orbis Terrarum, Buenos Aires: Miño y Dávila.

Martínez Pérez, Rosa María (2016). “Los corsarios ingleses y la provisión para el viaje de circunnavegación de Francis Drake, 1577-1580", Legajos 9 Boletín AGN, octava época, año 3 (enero-abril 2016), pp. 77-115.

Martinic, Mateo (2012). “Los holandeses en las Islas de los Pingüinos (15991615)", en Magallania, vol. 40 (2), pp. 7- 22. En línea: https://scielo.conicyt.cl/scielo.php?script=sci arttext\&pid=S0718-

22442012000200001\#n5 (consultado el 31/07/2019):

Martinic, Mateo (1998). “Drake y el descubrimiento de la insularidad fueguina. La evidencia cartográfica", en Anales del Instituto de la Patagonia, Serie Ciencias, núm. 26, pp. 5-22

Nuttall, Zelia (ed.) (1914). New Light on Drake. A Collection of Documents Relating to his Voyage of Circumnavigation, 1577-1580, London: Hakluyt Society.

Pagden, Anthony (2001 [1998]). “The Struggle for Legitimacy and the Image of Empire in the Atlantic to c. 1700", en Canny, Nicholas (ed.). The Origins of Empire. British Overseas Enterprise to the Close of the Seventeenth Century. Vol. 1 de "The Oxford History of the British Empire" (5 vols.), Oxford: Oxford University Press, pp. 34-54.

Parry, John H. (1984). "Drake and the World Encompassed", en Thrower, Norman (ed.), Sir Francis Drake and the famous voyage, 1577-1580, Los Angeles: University of California, pp. 1-11.

Penhos, Marta N. (2018). Paisaje con figuras. La invención de Tierra del Fuego a bordo del Beagle (1826-1836), Buenos Aires: Ampersand.

Quinn, David B. (1996). Sir Francis Drake as Seen by his Contemporaries, Providence: The John Carter Brown Library.

Quinn, David B. y Ryan, Anthony N. (1983). England's Sea Empire, 1550-1642, London: George Allen and Unwin. 
Quinn, David B., Armstrong, C. E., y Skelton, R. A. (1974). “The primary Hakluyt bibliography", en Quinn, David B. (ed.) The Hakluyt Handbook, 2 vols., London: Hakluyt Society, pp. II- 461-575.

Quinn, David B. y Quinn, Alison M. (1974). “Contents and sources of the three major works", en Quinn, David B. (ed.), The Hakluyt Handbook, 2 vols., London: Hakluyt Society, pp. II-333-460.

Quinn, David B. (1974). "Hakluyt's reputation", en Quinn, David B. (ed.) The Hakluyt Handbook, 2 vols., London: Hakluyt Society, pp. I: 133-152.

Silverberg, Robert (1997 [1972]). The Longest Voyage. Circumnavigators in the Age of Discovery, Athens: Ohio University Press.

Taylor, E. G. R. (1930). “The Missing Draft of Drake's Voyage of 1577-80”, in The Geographical Journal, vol. 75, núm. 1 (January 1930), pp. 46-47.

Twiss, Travers (1846). The Oregon Question Examined, in Respect to Facts and the Law of Nations, London: Longman, Brown, Green, and Longmans.

Van Groesen, Michiel (2008). "The De Bry Collection of Voyages (1590-1634): Earl America reconsidered", in Journal of Early Modern History 12 (2008), pp. 124.

Voigt, Lisa (2009). Writing Captivity in the Early Modern Atlantic. Circulations of Knowledge and Authority in the Iberian and English Imperial Worlds, Chapel Hill: University of North Carolina Press.

Wallis, Helen (1984). “The Cartography of Drake's Voyage”, en Thrower, Norman (ed.) Sir Francis Drake and the famous voyage, 1577-1580, Los Angeles: University of California, pp. 121-163.

Wallis, Helen (1974). "The Pacific", en Quinn, David B. (ed.) The Hakluyt Handbook, 2 vols., London: Hakluyt Society, pp. I: 223-233.

Wallis, Helen (1951). "The First English Globe: A Recent Discovery", in The Geographical Journal, vol. 117, núm. 3 (Sept. 1951), pp. 275-290. 